\title{
Sound Transmission Loss Properties of Truss Core
}

\section{Extruded Panels}

\author{
Yumei Zhang ${ }^{1,2}$, David Thompson ${ }^{2}$, Giacomo Squicciarini ${ }^{2}$, Jungsoo Ryue ${ }^{3}$, Xinbiao Xiao ${ }^{1}$, \\ Zefeng Wen ${ }^{1^{*}}$ \\ ${ }^{1}$ State Key Laboratory of Traction Power, Southwest Jiaotong University, Chengdu, China \\ ${ }^{2}$ Institute of Sound and Vibration Research, University of Southampton, Southampton, UK \\ ${ }^{3}$ School of Naval Architect and Ocean Engineering, University of Ulsan, Ulsan, Korea \\ e-mail: zfwen@home.swjtu.edu.cn
}

\begin{abstract}
The car body structures of modern trains are often formed of extruded aluminium panels. Their acoustic properties, particularly the sound transmission loss, have an important influence on the interior acoustic environment. In order to study the acoustic performance of extruded panels, their Sound Transmission Loss (STL) is studied using the coupled Wavenumber Finite Element method (WFE) and Wavenumber Boundary Element method (WBE). The damping of a typical structure is first measured in the laboratory to give suitable input values for the model. The predicted STL is compared with corresponding measurements of the sample panel, with good agreement above 400 Hz. Based on the validated model, an extensive parametric study is carried out to investigate the effect of different reinforcement rib styles on the STL. The effect of using extruded panels with rectangular, triangular and trapezoidal truss-core sections is studied in detail. Among the parameters studied, the number of bays in a given width has a great influence on the sound insulation. Considering practical use, both the mass and stiffness of each case are also considered. To give increased understanding of the STL behaviour, the dispersion curves are also studied. It is found that structures with better STL usually have fewer free wavenumbers below the acoustic wavenumber. For the same number of structural bays, a panel with triangular stiffening has the highest strength but also the largest mass, whereas a structure with rectangular stiffening has the least strength and lowest mass. In the evaluation, the weighted STL $R_{w}$ and the spectral adaptation term $C_{\text {tr }}$ are considered. The results are also considered relative to a mass law adjustment of the STL. It is found that the three cases which give the best results are a triangular rib panel with 4 or 5 bays in a $1 \mathrm{~m}$ width, and a trapezium case with 5 bays and inclination angle $25^{\circ}$. These have an $R_{w}$ that is $2 \sim 6 \mathrm{~dB}$ better than the reference panel, a smaller mass and a higher stiffness.
\end{abstract}

Keywords sound transmission loss; extruded panels; wavenumber finite element; wavenumber boundary element; dispersion 


\section{Introduction}

With the increase of train speeds, interior noise has become an important issue to be resolved in the further development of high speed trains [1], [2]. Most high-speed trains are constructed from truss core extruded aluminium panels as these provide high strength for a low weight. These panels play an important role in the transmission of noise to the vehicle interior through both airborne and structure-borne paths [3], [4]. Their acoustic performance has been widely studied and is known to be relatively poor, giving higher sound transmission than a homogeneous panel of the same mass [5].

Due to the complexity of the rib-stiffened built-up panel structure, a number of different methods have been investigated for studying their acoustic performance [6]. Conventional finite element methods (FEM) can only be used at relatively low frequencies due to the short bending wavelengths in the face plates. Shaw [5] and Xie et al. [7] therefore estimated the sound transmission behaviour of extruded panels using statistical energy analysis (SEA). Besides the extruded panel, Orrenius [8] also used SEA to evaluate the STL of a train floor, including a floating floor assembly. SEA is also effective in predicting the interior noise of the whole railway vehicle at middle and high frequencies [9]. However, the SEA method has limitations at low frequencies where the modal density and mode count of the structures are low. To overcome these limitations, Langley \& Bremner [10] introduced a hybrid FEM and SEA method, and Cotoni et al. [11] extended it to periodic structures with applications to the STL simulation of various panels. The periodic cell method is also an effective way to simulate the STL of large periodic or near periodic structures. Kohrs [12] [14] used the periodic cell method to study the structure-borne noise and dispersion characteristics of extruded panels. Cotoni et al. [11] and Orrenius et al. [15] compared these various methods for determining the STL loss of extruded railway floor panels and stiffened aircraft fuselage structures. Wang et al. [16] calculated the STL of infinite panels with regular vertical stiffeners based on a wave method. Lu et al. [17] used a space-harmonic method to study the transmission loss of orthogonally rib-stiffened panels with regular vertical reinforcement as well as the sound transmission across sandwich structures with periodic corrugated cores.

The Wavenumber Finite Element and Wavenumber Boundary Element (WFE-WBE) method has also been used to calculate the sound insulation of extruded sections. The WFE method uses finite elements to simulate the finite-width structure in a two-dimensional (2D) cross-section and uses a wave method to simulate the infinite structure in the third direction. Therefore, this method can simulate both different boundary conditions and irregular stiffening forms in the 2D cross-section, and can also consider the response in the third direction assuming invariant geometry and a long length. The number of degrees of freedom and the calculation effort are much reduced compared with a fully 3D method. The sound radiation and transmission can be studied by coupling the WFE model with WBE. Prasetiyo [18] used this method to calculate the STL of a semi-infinite single panel, double panel and a structure with vertical stiffeners as used in lightweight building structures Nilsson et al. [19] and Kim et al. [20] further considered irregularly reinforced structures, and established a model of the sound insulation of a section of train floor, which gave good agreement with measurements.

The reinforcement style of a ribbed panel is essential in the structural design of an extruded panel. On the basis of this WFE-WBE model [19] [22], this paper aims to investigate the dependence of the sound insulation on the different types of rib style. The sound insulation 
properties are investigated of extruded panels with regular rectangular, triangular and trapezoidal stiffeners in various configurations. Before performing the parameter study, the damping of a sample of extruded aluminium panel was first measured, as discussed in section 2. Following this, the WFE-WBE model is validated in section 3 by comparing the calculated STL with measurements. The parameter study of the effect of different rib styles on the STL is presented in section 4.

\section{Measurement of damping loss factor}

The damping loss factor of the structure is an input required by the model. To find practical values, the damping of an extruded panel is investigated experimentally. More details of the experimental methods are given in Appendix A.

The measurements have been performed on a sample of an extruded aluminium panel of a train floor structure with dimensions of $1.0 \times 1.5 \times 0.07 \mathrm{~m}$. The cross-section is shown in Figure 1 . The specimen consists of two face plates and 18 rib plates. The thickness of the various plates has been measured as $2.54 \pm 0.2 \mathrm{~mm}$. One of the face plates additionally has a $4 \mathrm{~mm}$ thick rubber layer attached to it. The bare face plate (face plate 1 ) is divided into six main bays by the stiffening plates, while the face plate with the rubber layer (face plate 2) is divided into eight bays, as indicated in Figure 1.

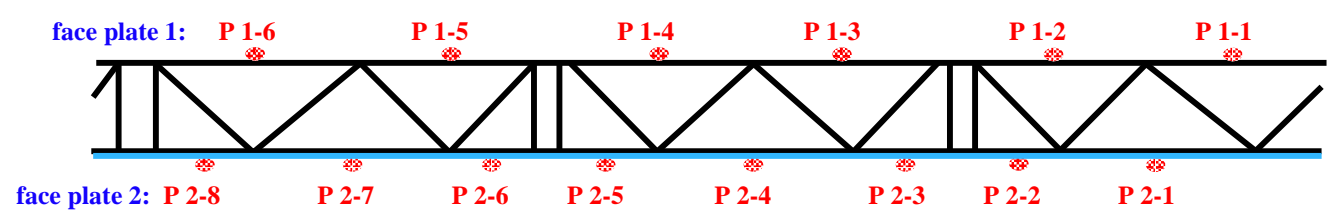

Figure 1 Sectional view of point mobility measurement of each bay

Results are obtained for each bay, as shown in Figure 2 and Figure 3 and for the two sides of the panel.

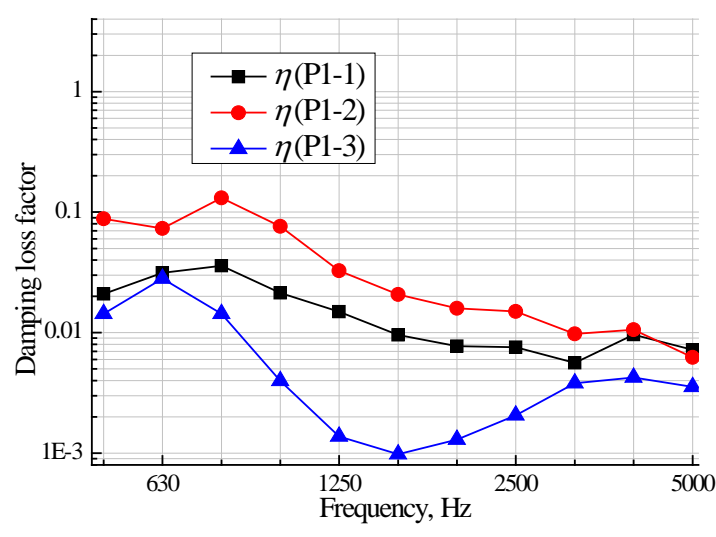

(a)

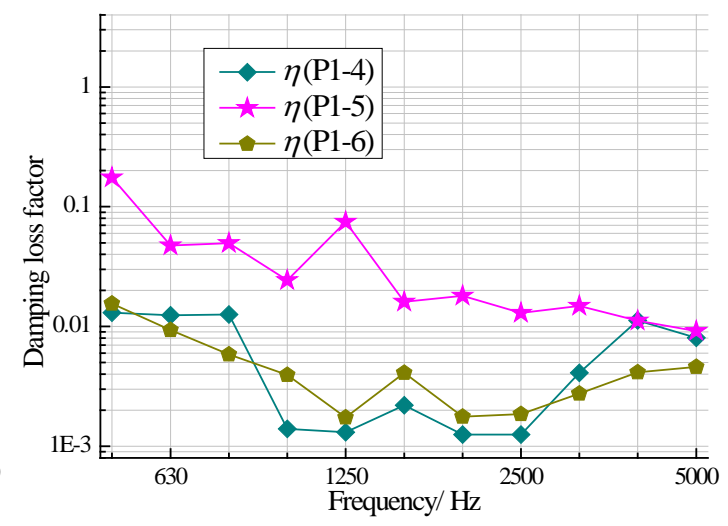

(b)

Figure 2 Damping loss factor of bare face plate based on energy method. (a) P1-1 P1-3, (b) P1-4 P1-6 


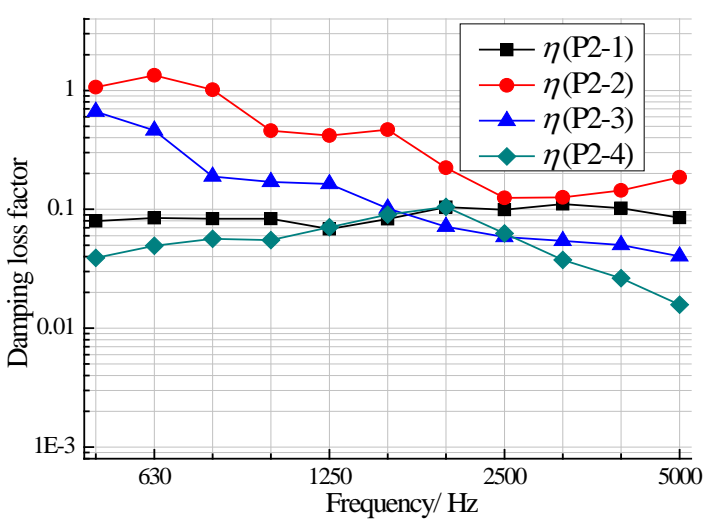

(a)

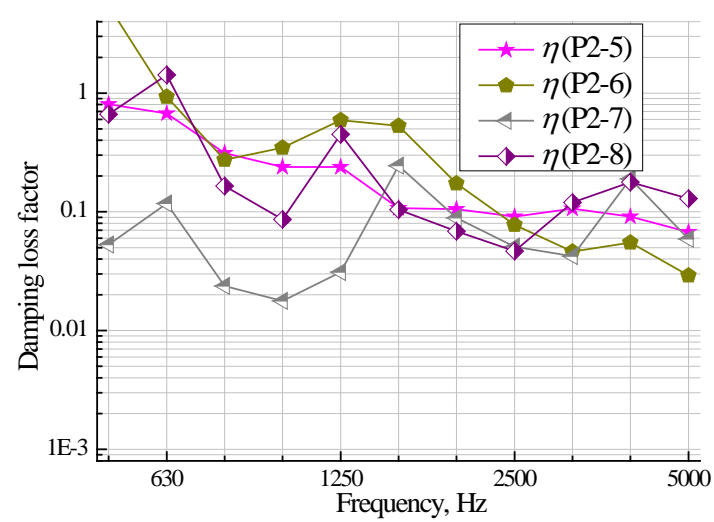

(b)

Figure 3 Damping loss factor of face plate with attached rubber layer based on energy method. (a)

$$
\text { P2-1 P2-4, (b) P2-5 P2-8 }
$$

The damping loss factor of the bare face plate lies in the range 0.001 to 0.1 , while that of the face plate with attached rubber layer lies between 0.01 and 1 . In addition to the rubber layer, the proximity to the stiffeners has a great influence on the damping loss factor of each bay. Thus, for example, bays P1-3 and P1-4 have much lower loss factors than P1-2 and P1-5 even though they are all on the bare face plate P1. This illustrates that large variations are possible, although it would appear that this is related to the particular features of the panel under test. In particular there is a joint between the vertical stiffeners between P1-2 and P1-3 and between P1-4 and P1-5 which may be a source of additional damping. There is a small separation between the diagonal stiffener and the vertical one at the outer edge of P1-3 and P1-4 which appears to isolate them from the influence of the joint, leading to lower damping in these strips.

\section{STL of extruded panel}

Extruded panels used in train construction are complex built-up structures. A WFE-WBE model of the extruded panel is built and used to study the STL property of the panel through simulations. First, the WFE-WBE method is briefly introduced.

\subsection{WFE-WBE theory}

An example of a single panel, infinite in one direction (the $x$ direction), is shown in Figure 4. Using the WFE method, each plate element has four degrees of freedom (DOF) at each node. They are three displacements $u, v, w$, in the $x, y, z$ directions respectively, and the rotation $\phi$ around the $x$ axis [19] [22].

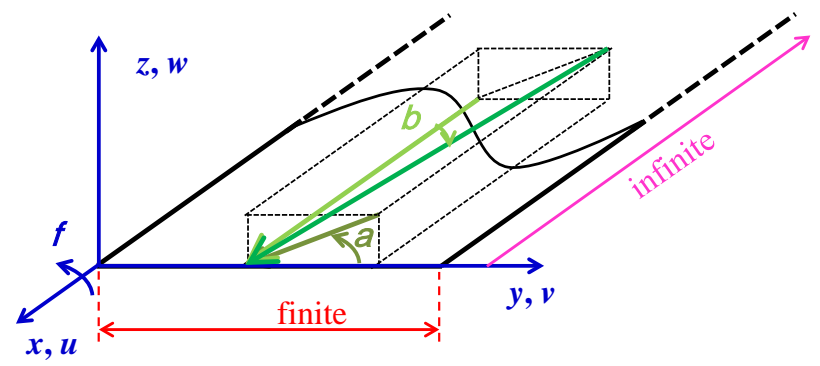

Figure 4 Semi-infinite panel and definition of coordinates 
For a structure excited by a force vector $\mathbf{F}$ at angular frequency $\omega$, the equation of motion is:

$$
\left[\mathbf{K}_{4} \frac{\partial^{4}}{\partial x^{4}}+\mathbf{K}_{2} \frac{\partial^{2}}{\partial x^{2}}+\mathbf{K}_{1} \frac{\partial}{\partial x}+\mathbf{K}_{0}-\omega^{2} \mathbf{M}\right] \mathbf{W}(x)=\mathbf{F}(x)
$$

where $\mathbf{K}_{j}(j=0,1,2,4)$ are stiffness matrices, $\mathbf{M}$ is the mass matrix and $\mathbf{W}$ is the displacement vector. Applying Fourier transforms with respect to $x$ to both the displacement and force gives

$$
\begin{aligned}
& \tilde{\mathbf{W}}(\kappa)=\int_{-\infty}^{\infty} \mathbf{W}(x) \mathrm{e}^{\mathrm{i} \kappa x} \mathrm{~d} x \\
& \tilde{\mathbf{F}}(\kappa)=\int_{-\infty}^{\infty} \mathbf{F}(x) \mathrm{e}^{\mathrm{i} \kappa x} \mathrm{~d} x
\end{aligned}
$$

where $\kappa$ is the structural wavenumber in the $x$ direction. Applying this to equation (1), the wavenumber finite element equation is obtained:

$$
\left[(-\mathrm{i} \kappa)^{4} \mathbf{K}_{4}+(-\mathrm{i} \kappa)^{2} \mathbf{K}_{2}+(-\mathrm{i} \kappa) \mathbf{K}_{1}+\mathbf{K}_{0}-\omega^{2} \mathbf{M}\right] \tilde{\mathbf{W}}(\kappa)=\tilde{\mathbf{F}}(\kappa)
$$

which can also be written as:

$$
\left[\mathbf{K}(\kappa)-\omega^{2} \mathbf{M}\right] \tilde{\mathbf{W}}(\kappa)=\tilde{\mathbf{F}}(\kappa)
$$

with

$$
\mathbf{K}(\kappa)=\sum_{j=0,1,2,4} \mathbf{K}_{j}(-\mathrm{i} \kappa)^{j}
$$

When coupled with the wavenumber boundary element equations this becomes:

$$
\begin{gathered}
\left\{\mathbf{K}(\kappa)-\omega^{2} \mathbf{M}\right\} \tilde{\mathbf{W}}(\kappa)=\tilde{\mathbf{F}}(\kappa)+\mathrm{i} \omega \rho_{0} \mathbf{C}_{\mathbf{1}} \tilde{\boldsymbol{\Psi}} \\
\mathbf{H} \tilde{\boldsymbol{\Psi}}-\mathbf{G} \frac{\partial \tilde{\boldsymbol{\Psi}}}{\partial \mathbf{n}}=\frac{\tilde{\mathbf{P}}_{\text {in }}}{\mathrm{i} \omega} \\
\mathbf{I} \frac{\partial \tilde{\boldsymbol{\Psi}}}{\partial \mathbf{n}}-\mathrm{i} \omega \mathbf{C}_{2} \tilde{\mathbf{W}}(\kappa)=0
\end{gathered}
$$

where $\tilde{\mathbf{P}}_{\text {in }}$ is the acoustic pressure excitation, $\rho_{0}$ is the density of fluid and $\mathbf{C}_{1}$ denotes the coupling matrix between the WFEs and WBEs. $\mathbf{H}$ and $\mathbf{G}$ are matrices of Green's functions. $\tilde{\boldsymbol{\Psi}}$ and $\partial \tilde{\boldsymbol{\Psi}} / \partial \mathbf{n}$ are the velocity potential and the normal velocity at the nodes of the boundary elements. $\mathbf{n}$ represents the normal directional vector of WBEs. $\mathbf{I}$ is an identity matrix and $\mathbf{C}_{2}$ is a matrix allocating fluid-coupled DOFs in $\tilde{\mathbf{W}}$.

By solving equations (7) (9), the acoustic pressure $\tilde{p}(\kappa)$ and fluid particle velocity $\tilde{v}(\kappa)$ at the fluid nodes in the wavenumber domain are obtained from:

$$
\tilde{p}(\kappa)=\mathrm{i} \omega \rho_{0} \tilde{\boldsymbol{\Psi}}
$$




$$
\tilde{v}(\kappa)=-\frac{\partial \tilde{\boldsymbol{\Psi}}}{\partial \mathbf{n}}
$$

For an incident plane wave with orientation defined by the angles $\alpha$ and $\beta$ as shown in Figure 4, the incident power $W_{i}$ and transmitted power $W_{t}$ can be obtained in the wavenumber domain as [20]

$$
\begin{gathered}
W_{i}(\alpha, \beta)=\frac{1}{2} \int_{\Gamma} \frac{\left|\tilde{p}_{i}(\kappa)\right|^{2} \sin \alpha \sin \beta}{\rho_{0} c} \mathrm{~d} \Gamma \\
W_{t}(\alpha, \beta)=\frac{1}{2} \operatorname{Re}\left(\int_{\Gamma} \tilde{p}_{t} *(\alpha, \beta) \tilde{v}_{t}(\alpha, \beta) \mathrm{d} \Gamma\right)
\end{gathered}
$$

The sound transmission coefficient $\tau(\alpha, \beta)$ can be calculated as

$$
\tau(\alpha, \beta)=\frac{W_{t}(\alpha, \beta)}{W_{i}(\alpha, \beta)}
$$

For diffuse incidence, the transmission coefficient $\tau_{\mathrm{d}}$ is given by [20]

$$
\tau_{\mathrm{d}}=\frac{\int_{0}^{\pi / 2} \int_{0}^{\pi / 2} \tau(\alpha, \beta) \sin ^{2} \beta \sin \alpha \mathrm{d} \alpha \mathrm{d} \beta}{\int_{0}^{\pi / 2} \int_{0}^{\pi / 2} \sin ^{2} \beta \sin \alpha \mathrm{d} \alpha \mathrm{d} \beta}
$$

The STL is then given by

$$
R=10 \log _{10}\left(\frac{1}{\tau_{\mathrm{d}}}\right)
$$

\subsection{Model validation}

The STL model of the aluminium extruded panel is illustrated in Figure 5. The structure is defined by isotropic plate finite elements. These elements include in-plane extensional and shear motion as well as bending. In the tests described in [20] the edges of the panel were attached to a stiff frame. These conditions are somewhere between clamped and simply supported but for simplicity here the four nodes at the corners of the structure in the model are clamped. The density, Poisson's ratio and Young's modulus of the aluminium are $2700 \mathrm{~kg} / \mathrm{m}^{3}, 0.3$ and $70 \mathrm{GPa}$ respectively. The elements shown in blue include the effect of the heavy rubber layer through an increased density, based on the density for the rubber layer of $1500 \mathrm{~kg} / \mathrm{m}^{3}$ [20]; the bending stiffness of the rubber layer is neglected as it is at least one or two orders of magnitude smaller than that of the aluminium.

It is recognised that the fillets at the joints between ribs can introduce some additional stiffening, as discussed by Kohrs [14]. However, to include them in the model would require a much more detailed model based on solid elements, so they are neglected in the current plate model to keep the model size practical.

For the sake of simplicity, based on the measured damping loss factors shown in Figure 2 and Figure 3 , the damping loss factor of the aluminium plates in the model is set to 0.005 , and the 
damping loss factor of the plates with the added rubber layer is set to 0.02. Boundary elements on either face of the panel are shown in black. These use the half-space acoustic Green's function allowing the mesh to be truncated at the edges of the structure. The air within the internal spaces is neglected in the model as the results of an initial investigation showed that this has a negligible influence on the STL.

The calculated diffuse incidence STL is shown in Figure 6; the measured results from [20] are shown for comparison. The simulation result is not exactly the same as that presented in [20], especially at frequencies around $100 \mathrm{~Hz}$. Although both studies made use of the same software and are based on the same physical panel, they were carried out independently. The differences in the results may be because of small differences in the measured geometry. The angles $\alpha$ and $\beta$ considered in Eq. (15) both cover the range from $2^{\circ}$ to $90^{\circ}$ in steps of $8^{\circ}$. It was verified that this was sufficient to obtain a converged result. The range of frequency is from $44 \sim 5620 \mathrm{~Hz}$ which covers the one-third octave bands of 50 5000 Hz with at least three frequency points per band. It is linear spaced from 44 up to $1208 \mathrm{~Hz}$ in steps of $4 \mathrm{~Hz}$, and it is log spaced from $1210 \mathrm{~Hz}$ to $5620 \mathrm{~Hz}$ with 160 frequencies. The STL results are given both in narrow bands and averaged into one-third octave bands. It can be seen that above $400 \mathrm{~Hz}$ the calculated STL agrees well with the measured one, although the STL is about $5 \mathrm{~dB}$ larger than the measured values in the 2500 and $3150 \mathrm{~Hz}$ frequency bands. In the range from $125 \mathrm{~Hz}$ to $315 \mathrm{~Hz}$, the STL based on the WFE-WBE method is $5 \sim 10 \mathrm{~dB}$ lower than the measured value, dropping to a minimum at $125 \mathrm{~Hz}$ which corresponds to the cut-on frequency of the first waves in the infinite panel. The value of $R_{\mathrm{w}}$ according to ISO $717-1$ [23] obtained from the simulations is $1.8 \mathrm{~dB}$ lower than the measured one. This difference is expected to be mainly due to the difference between the short length of the test specimen $(1.5 \mathrm{~m})$ and the infinitely long simulation model. In practice, although the comparison is made here with a short test specimen, it may be noted that the actual cabin of a high-speed train is about $25 \mathrm{~m}$ long, and the infinite model is expected to be a more reasonable representation of this than the short test specimen.

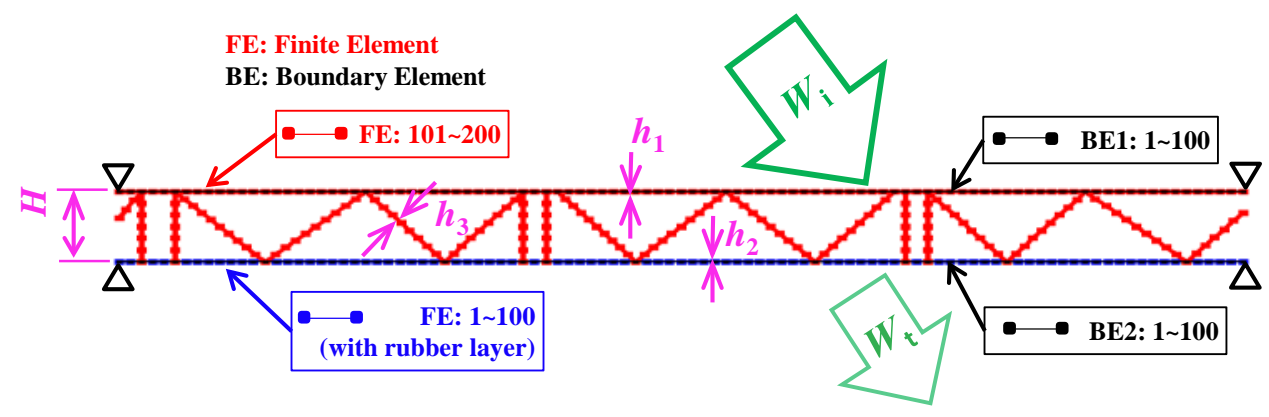

Figure 5 Model of extruded panel with rubber layer 


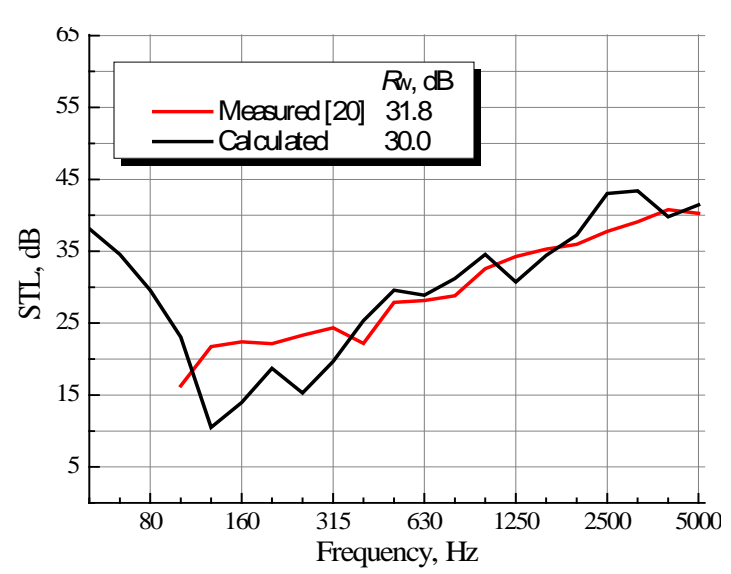

(a)

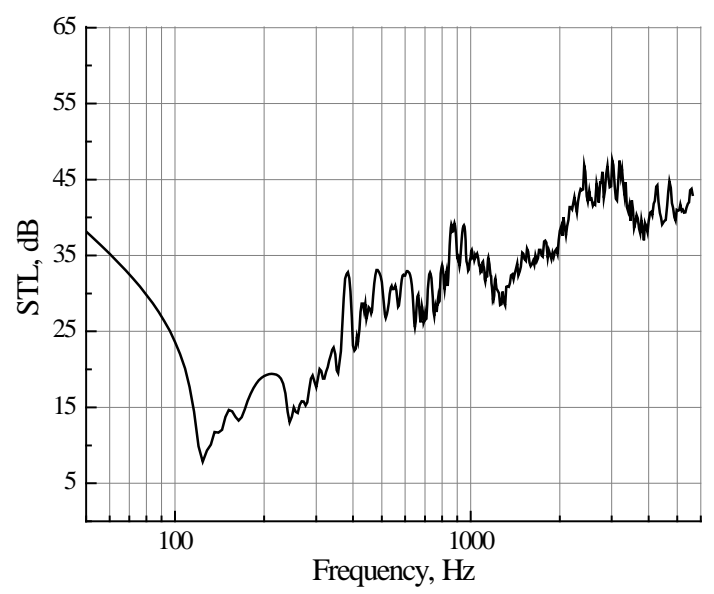

(b)

Figure 6 Diffuse incidence STL calculated in one-third octave bands and narrow band frequency steps, including comparison with measurements [20]. (a) One-third octave, (b) narrow band

\subsection{Influence of rubber layer on the STL}

In order to study the effect of the rubber layer on the STL, the STL property of a bare extruded panel is determined by removing the rubber layer from the model in Figure 5 (i.e. setting the density and loss factor to be equal to those on the other plates). The results are shown in Figure 7 in the form of the both one-third octave STL for diffuse incidence and narrow-band results for normal incidence. Normal incidence results are shown as this allows the response at discrete frequencies to be identified more easily. From this it can be seen that the rubber layer has a significant influence on the STL, giving a higher STL than when it is omitted over almost the whole frequency range. This reflects the effect of the added mass of the rubber layer as well as the higher loss factor. In particular at high frequency, above $1200 \mathrm{~Hz}$, the dips in the STL are greatly improved.

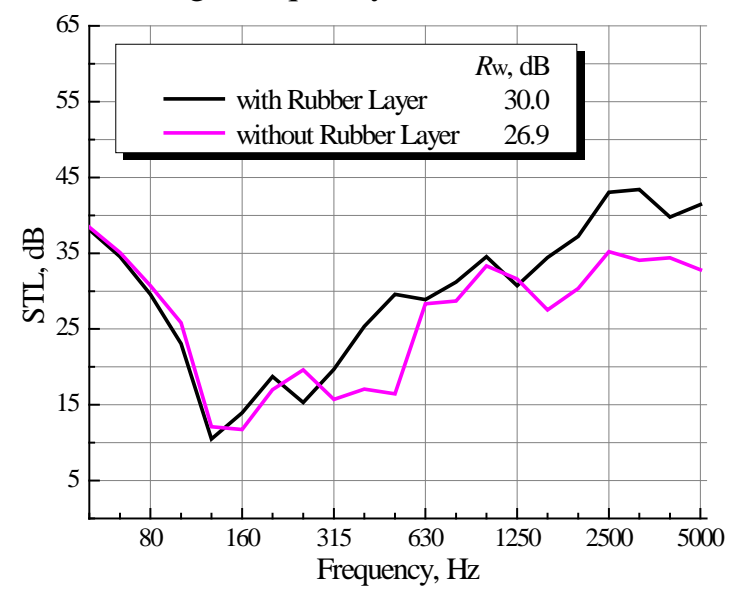

(a)

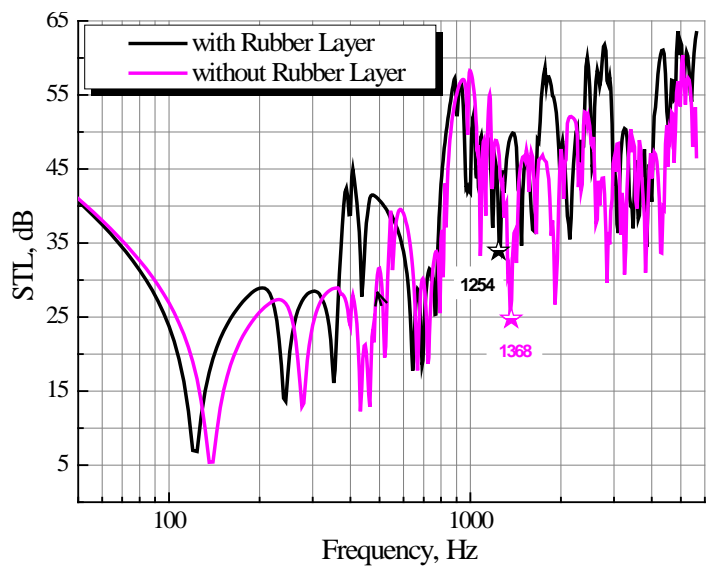

(b)

Figure 7 Comparison of STL of extruded panel with and without rubber layer. (a) One-third octave for diffuse incidence, (b) narrow band for normal incidence

The response is extracted at two close frequencies corresponding to dips of the normal incidence STL from the two models, $1254 \mathrm{~Hz}$ in the model with the rubber layer and $1364 \mathrm{~Hz}$ in the bare model. The displacements are shown in Figure 8 to the same magnification, from which it can be seen that the vibration shape and amplitudes of the incident plate (upper face plate) are similar for 
the two structures, whereas the amplitude of the displacement on the transmission surface with attached rubber layer is much smaller than that of the bare structure.

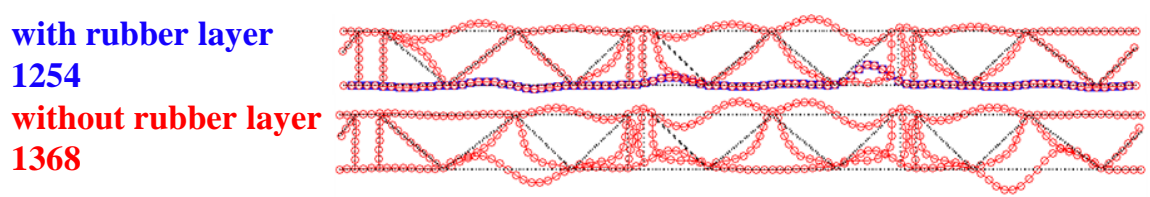

Figure 8 Comparison of the displacements at similar frequency for the models with and without rubber layer excited by normal incidence

In order to evaluate the separate effects of the mass and damping of the rubber layer, the STL of the structure only considering its added mass or damping are determined. The results are shown in Figure 9.

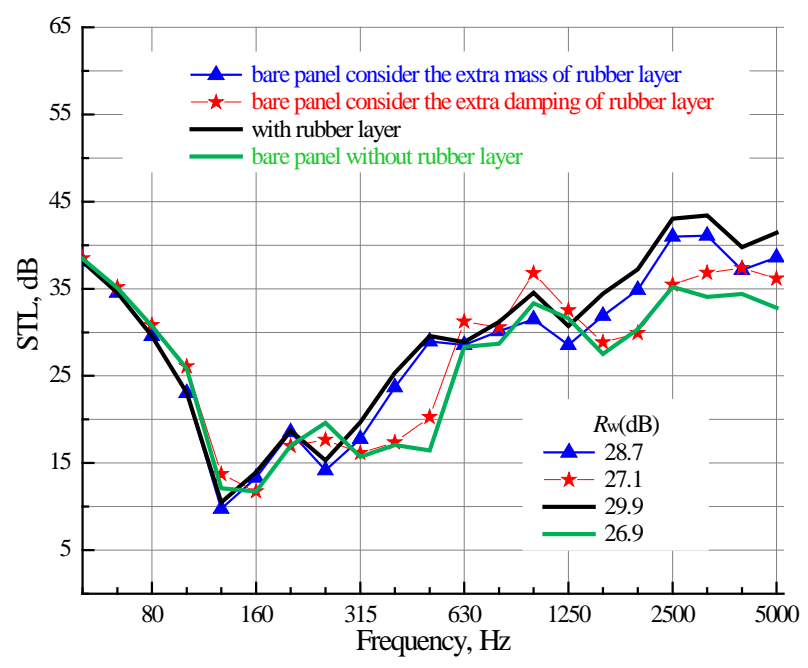

Figure 9 Comparison of the effect of mass and damping of rubber layer on diffuse incidence STL of extruded panel

Compared with the bare panel, simply increasing the damping loss factor of the face plate with the rubber layer from 0.005 to 0.02 , the STL is improved by $1 \sim 2 \mathrm{~dB}$ above $315 \mathrm{~Hz}$ and the corresponding $R_{\mathrm{w}}$ is improved by only $0.2 \mathrm{~dB}$. If instead the mass is increased to allow for the rubber layer and the damping loss factor is kept as 0.005, the STL increases at frequencies of $315 \sim 630 \mathrm{~Hz}$ and $1250 \sim 5000 \mathrm{~Hz}$ by up to $10 \mathrm{~dB}$ and the corresponding $R_{\mathrm{w}}$ is improved by $1.8 \mathrm{~dB}$. Since the added mass of the rubber layer is roughly the same as that of the bare face plate, this extra mass dominates the improvement of the STL of the extruded panel. Conversely the added damping corresponds to an increase by a factor of 4 of the damping of one side of the panel, but the overall damping of the panel is increased by much less than this.

\section{Parameter study}

Having established that the WFE-WBE model gives a reasonable match to the measured STL, in this section the effect of changing several parameters is considered. The parameters considered are the thickness of the various plates and the arrangement of the stiffeners. In addition to the STL, the corresponding static stiffness of the panel is determined. This is used as an indication of the load-bearing capacity of the panel in comparison with the baseline structure. The location chosen in 
each case to determine the stiffness is at a position on the face plate where it is connected to a rib plate, at or near the middle of the panel. These positions are chosen to reflect the overall panel stiffness as the stiffness is always greater at the ribs than between them. The overall mass per unit area is also determined.

The effect on the STL of changing the thickness of the various plates, as well as the overall thickness of the structure, is studied in Section 4.1 and the results are also compared with the bare reference extruded structure considered above, as shown in Figure 5 (but without the rubber layer). Various configurations of rectangular, triangular and trapezoidal stiffeners are then studied in Sections 4.2 4.4 in terms of their STL, overall mass and stiffness. For ease of comparison, all these regular structures have the same height $(0.07 \mathrm{~m})$ and plate thickness $(2.54 \mathrm{~mm})$ as the bare structure shown in Figure 5. The panel width is kept as $1 \mathrm{~m}$ in each case and the boundary condition is always clamped. Although the actual train floor is wider than this, the $1 \mathrm{~m}$ width is used to avoid excessive computation times. The effect of panel width is considered in Appendix B. The angles of incidence considered are same as before. To save calculation time, the frequency range is reduced except for the thickness study cases, for which it is same as before. The frequency range of the remaining cases is linear spaced up to $600 \mathrm{~Hz}$ with steps of $6 \mathrm{~Hz}$, and log spaced from 610 to 5600 $\mathrm{Hz}$ with 100 frequencies. This covers the one-third octave bands $80 \sim 5000 \mathrm{~Hz}$ with at least three frequencies per band. All the STL results are calculated for diffuse field excitation.

\subsection{Thickness}

The effect on the STL of changing the thickness of the various plates of the bare structure shown in Figure 5 is studied in this section. The thickness of the plate on the incident side $h_{1}$, on the transmitting side $h_{2}$, on both faces $h_{1}$ and $h_{2}$, and of the intermediate ribs $h_{3}$ are varied separately. Each is used in a range from $0.5 h_{0}$ to $1.5 h_{0}$ in steps of $0.25 h_{0}$, where $h_{0}(=2.54 \mathrm{~mm})$ is the plate thickness of the reference panel. The overall thickness of extruded panel $H$ is similarly varied from $0.7 H_{0}$ to $1.2 H_{0}$ in steps of $0.1 H_{0}$, where $H_{0}(=0.07 \mathrm{~m})$ is the thickness of the reference structure. As well as the STL in one-third octave frequency bands, the weighted STL, $R_{w}$, is determined according to ISO 717-1 [23]. This is determined from the STL values in the frequency bands from $100 \mathrm{~Hz}$ to $3150 \mathrm{~Hz}$. In addition the spectral adaptation term $C_{\text {tr }}$ (based on a source weighting representative of A-weighted traffic noise) is determined according to ISO 717-1 [23] and the alternative single number STL $R_{A 2}=R_{w}+C_{\text {tr }}$ is evaluated from it. Including both parameters helps to ensure that any conclusions based on the single numbers are not skewed by the particular definition of a single parameter. Contrary to the standard, these single number STL values are evaluated to the nearest $0.1 \mathrm{~dB}$. In order to allow for the dependence of the STL on the panel mass, the results are compared with the weighted STL of the bare extruded reference panel corrected by the panel mass, given by:

$$
R_{w, m}=20 \cdot \log _{10}\left(m / m_{0}\right)+R_{w 0}
$$

$m$ is the mass per unit area, $m_{0}\left(=24.9 \mathrm{~kg} / \mathrm{m}^{2}\right)$ is the mass per unit area of the bare reference panel as calculated from the FE geometry and $R_{w 0}(=26.9 \mathrm{~dB})$ is the weighted STL of the bare reference panel. When $R_{w}$ lies above this mass line, it means a better weighted STL is obtained for a particular mass than the reference structure. A similar mass correction is applied for $R_{A 2}$ of the bare extruded reference panel

$$
R_{A 2, m}=20 . \log _{10}\left(m / m_{0}\right)+R_{A 2,0}
$$


The weighted STL, in both the form of $R_{w}$ and $R_{A 2}$, and the panel stiffness are given in Figure 10 . It can be seen that an increase of the panel mass due to the change of the thickness always leads to an increase in the stiffness of the structure, while the same trend is not found for $R_{w}$ or $R_{A 2}$. When the thickness of the panel on the transmitting side $\left(h_{2}\right)$ is increased from the reference value, $R_{w}$ increases according to the mass law, while if the other three parameters are increased values of $R_{w}$ are obtained below the reference value. When each of the plate thicknesses is reduced to half their original values, $R_{w}$ is greater than the mass line. However, the stiffness is reduced to just over half the original value. Changing the overall structure thickness appears the least promising of the parameter changes considered here. In each case similar results are found for $R_{A 2}$ as the values of $C_{\text {tr }}$ are mostly between -4 and $-6 \mathrm{~dB}$.

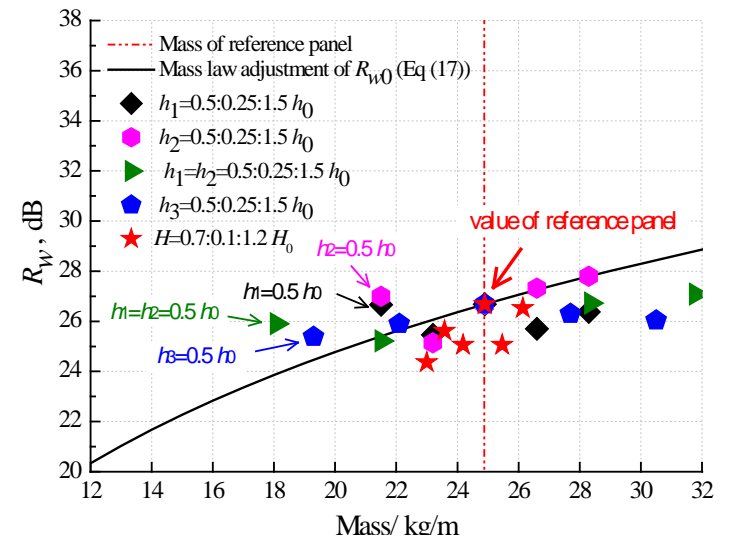

(a)

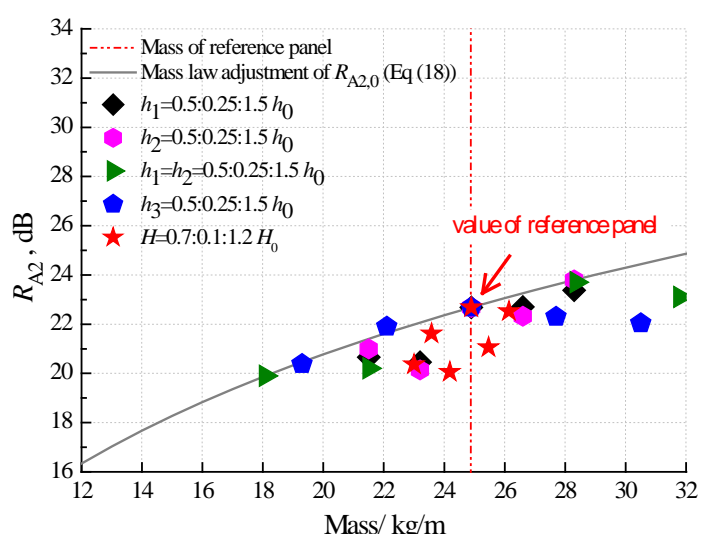

(b)

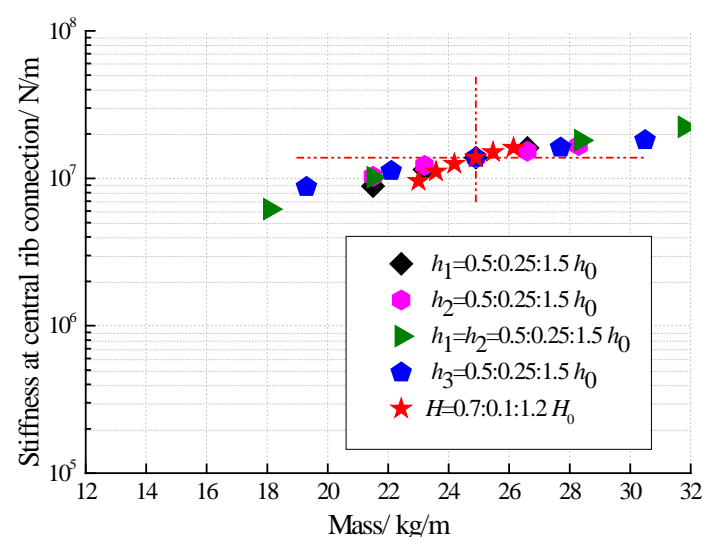

(c)

Figure 10 Weighted STL and stiffness for different thicknesses, plotted against panel mass per unit length. (a) $R_{w}$, (b) $R_{A 2}$ and (c) stiffness

The frequency-dependent STL for the three cases with plate thickness $0.5 h_{0}$ are compared with the reference result in Figure 11. It can be seen that the thinner structures have a higher STL than the reference structure at most frequencies above $315 \mathrm{~Hz}$. It can be noted that changes to $h_{1}$ and $h_{2}$ produce different effects as the panel geometry is not symmetric, as seen in Figure 5, whereas for a symmetric panel the effects would be identical. To help interpret these results, Figure 12 shows the dispersion curves for these four cases, obtained by solving Eq. (7) as an eigenvalue problem for frequency at given wavenumbers. The acoustic wavenumber is also shown for comparison; wavenumbers above the acoustic wavenumber will not radiate sound into the far field. The three 
cases with reduced thickness all have many more wavenumbers above the acoustic wavenumber which may be the reason for increased STL.

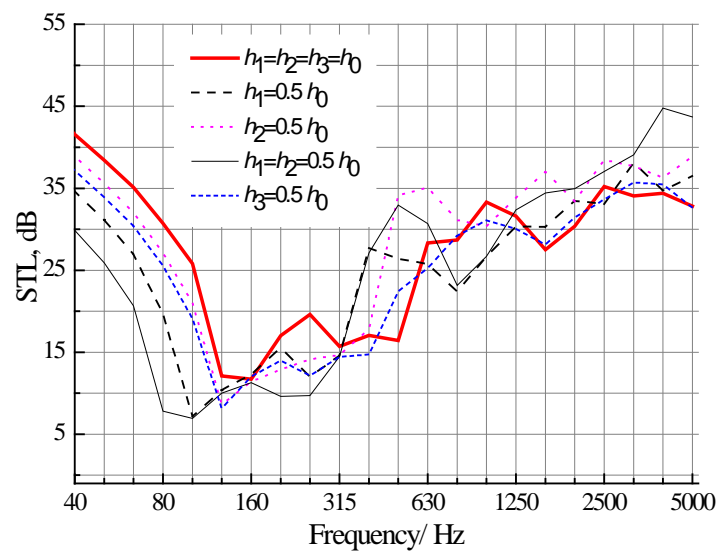

Figure 11 STL for reduced plate thickness of different plates

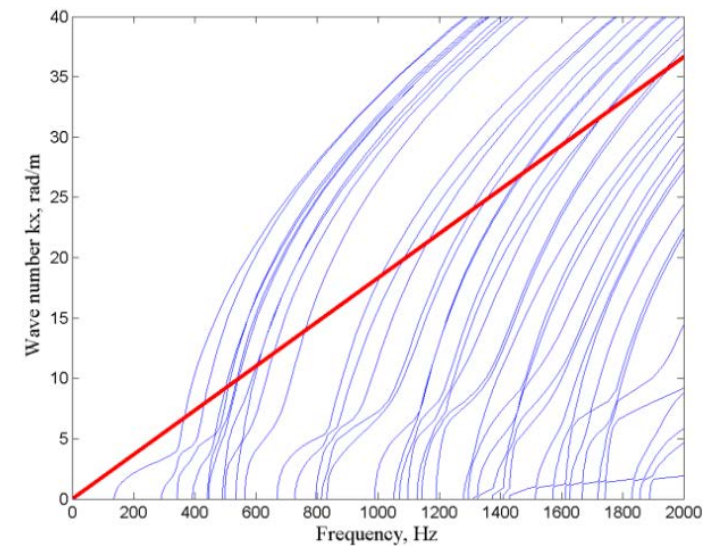

(a)

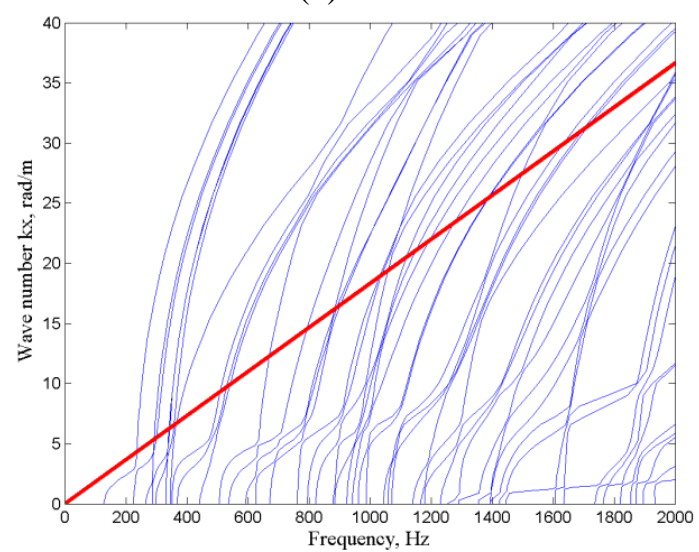

(c)

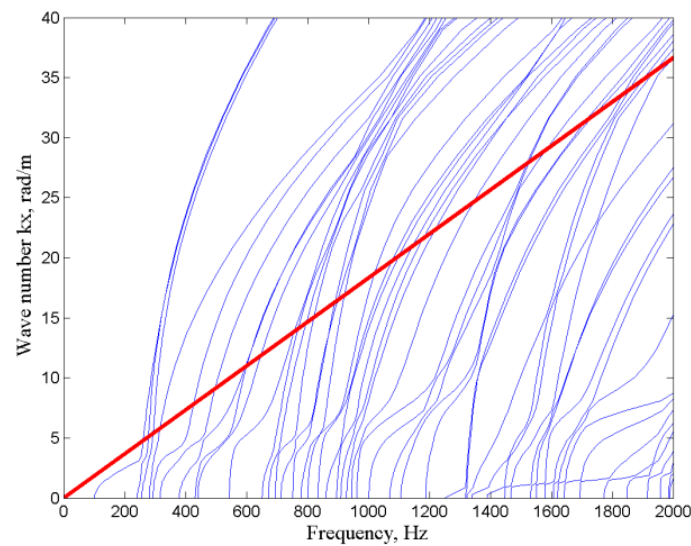

(b)

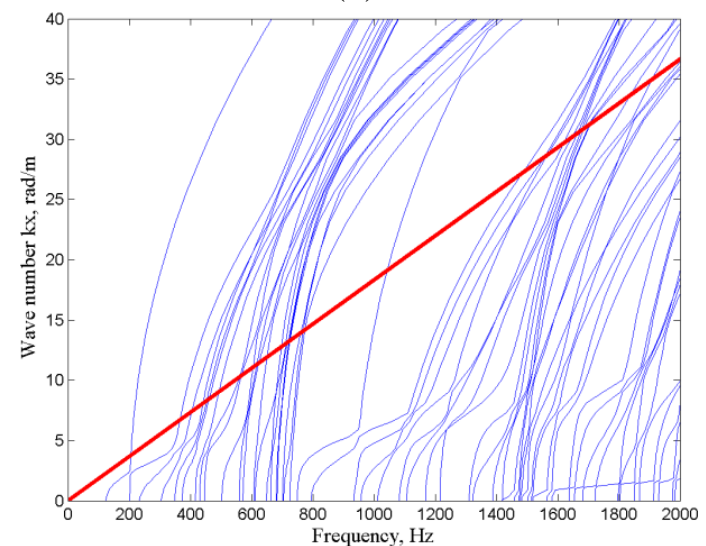

(d)

Figure 12 Dispersion characteristics for different thicknesses. (a) $h_{1}=h_{2}=h_{3}=h_{0}$, (b) $h_{2}=h_{3}=h_{0}, h_{1}=0.5 h_{0}$, (c) $h_{1}=h_{3}=h_{0}, h_{2}=0.5 h_{0}$ and (d) $h_{1}=h_{2}=h_{0}, h_{3}=0.5 h_{0}$

\subsection{Regular rectangular rib extruded panel}

Regular rectangular stiffened panels are considered in this section, the structure of which can be specified by a single parameter, the number of bays in the $1 \mathrm{~m}$ width. Three examples are shown in Figure 13. The weighted sound reduction is investigated for 12 cases with between 2 and 24 bays 
with a step size of 2. The STL results are shown in Figure 14. All the cases studied have smaller mass than the reference panel while some of them have a higher STL. The stiffness increases with the mass but is much lower than the reference panel, even for a mass similar to the reference panel.

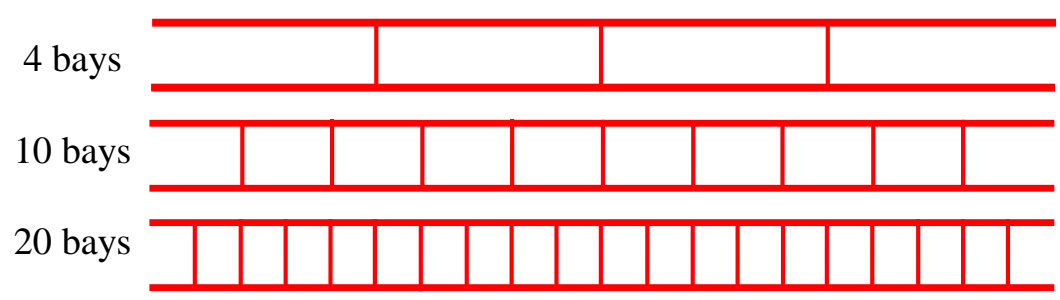

Figure 13 Examples of rectangular rib structures with 4, 10 and 20 bays

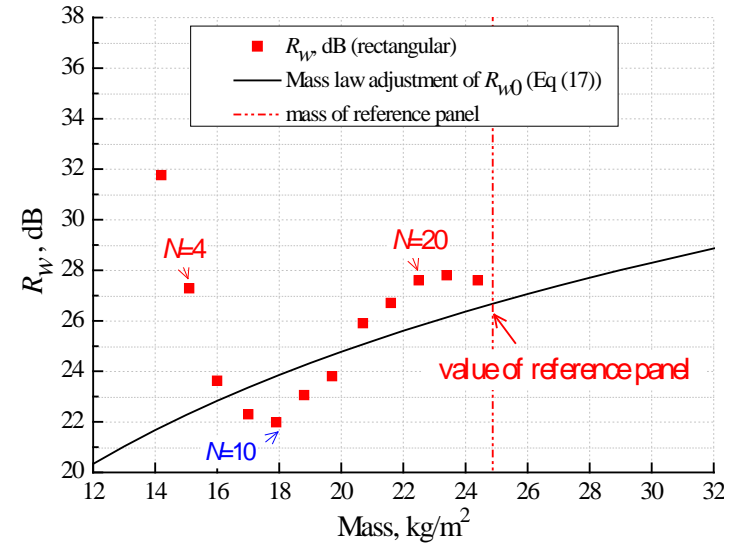

(a)

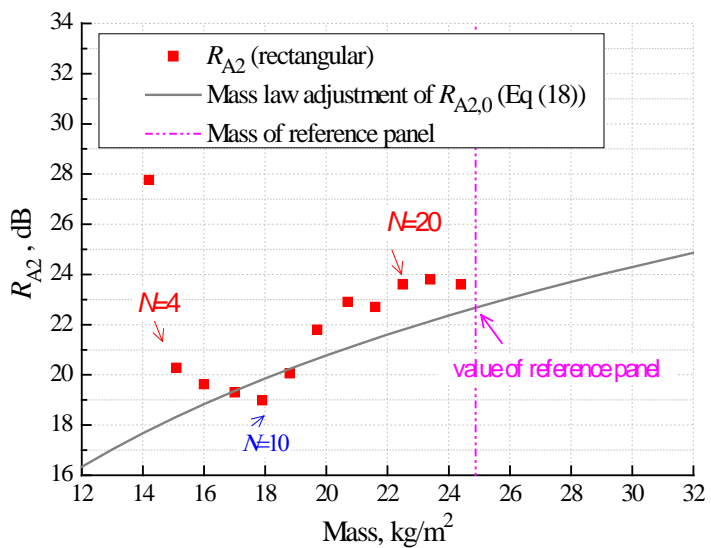

(b)

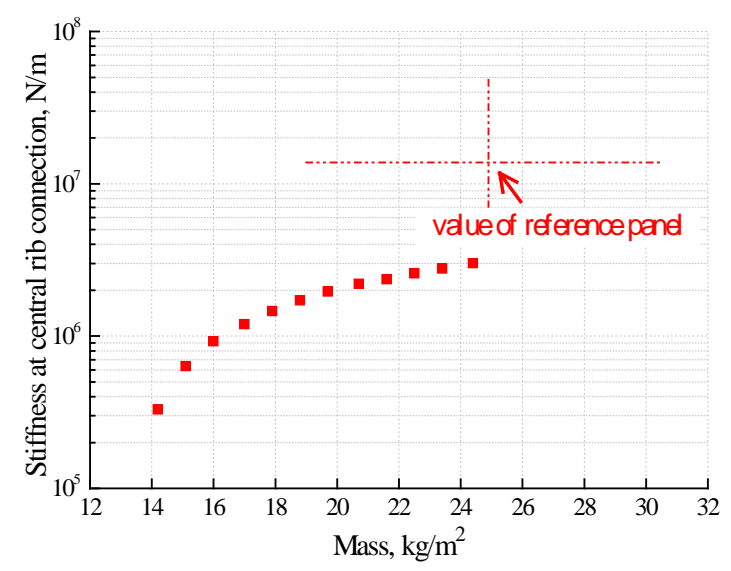

(c)

Figure 14 Weighted STL and stiffness of rectangular rib structures. (a) $R_{w}$, (b) $R_{A 2}$ and (c) stiffness

As the number of bays is increased, the weighted STL first decreases, reaching a minimum value at $N=10$ bays. As the number is further increased, the weighted STL grows again, reaching a maximum at $N=22$ in $R_{w}$ or $R_{\mathrm{A} 2}$. In order to explain this phenomenon, three structures are selected, two with similar sound insulation, i.e., those with 4 and 20 bays, and the configuration with the minimum STL, that with 10 bays (see Figure 13). The mass, stiffness, first cut-on frequency and weighted sound insulation $R_{w}$ and $R_{\mathrm{A} 2}$ of the three structures are shown in Table 1 .

As shown in Table 1, the weighted STL of both the 4 and 20 bay extruded panels is around 27.5 $\mathrm{dB}$ which lies above the mass line. The corresponding frequency-dependent sound insulation is 
shown in Figure 15. It can be seen that the main difference between the STL affecting the value of $R_{\mathrm{w}}$ in Table 1 of the three structures is between the 200 and $2000 \mathrm{~Hz}$ frequency bands. The first cut-on frequency increases with the number of bays, corresponding to the increase in stiffness seen in Figure 15(c). Although the weighted STL of the 4 and 20 bay structures are quite similar, the STL of the 20-bay structure varies much less with frequency than that of the 4-bay structure. Consequently $R_{\mathrm{A} 2}$ for the 20-bay structure is higher than for the 4-bay one.

Table 1 Details of rectangular rib structure with 4, 10 and 20 bays

\begin{tabular}{|c|c|c|c|c|c|}
\hline $\begin{array}{c}\text { Number of bays } \\
(N)\end{array}$ & $\begin{array}{c}\text { Mass per unit } \\
\text { area }\left(\mathrm{kg} / \mathrm{m}^{2}\right)\end{array}$ & $\begin{array}{c}\text { Stiffness } \\
(\mathrm{N} / \mathrm{m})\end{array}$ & $\begin{array}{c}\text { First cut-on } \\
\text { frequency }(\mathrm{Hz})\end{array}$ & $R_{w}(\mathrm{~dB})$ & $R_{\mathrm{A} 2}(\mathrm{~dB})$ \\
\hline 4 & 15.1 & $6.35 \times 10^{5}$ & 23 & 27.3 & 20.3 \\
\hline 10 & 17.9 & $1.46 \times 10^{6}$ & 41 & 22.0 & 19.0 \\
\hline 20 & 22.5 & $2.58 \times 10^{6}$ & 56 & 27.5 & 23.5 \\
\hline Reference panel & 24.9 & $1.38 \times 10^{7}$ & 137 & 26.9 & 22.7 \\
\hline
\end{tabular}

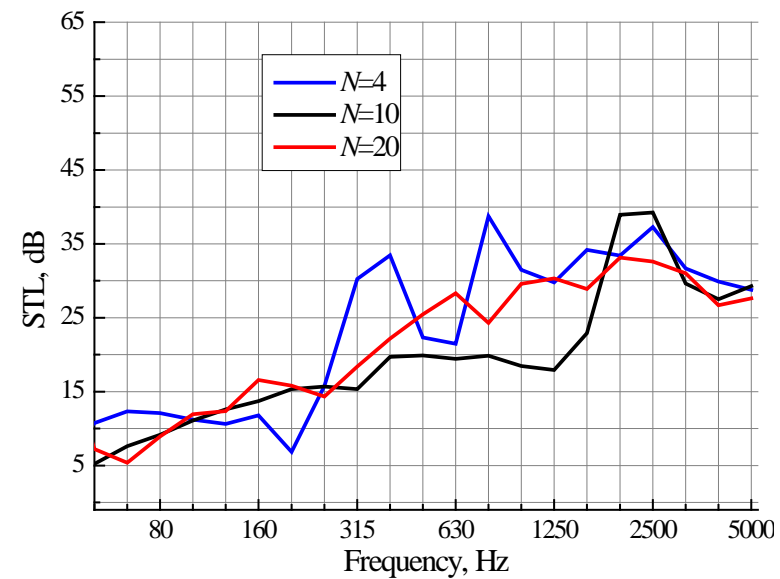

(a)

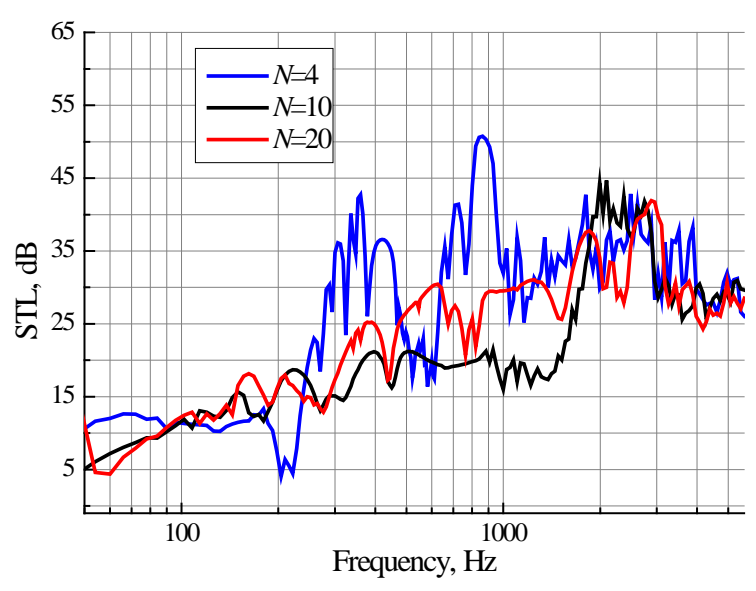

(b)

Figure 15 STL of rectangular rib structures with 4, 10 and 20 bays for diffuse incidence. (a) One-third octave, (b) narrow band

The dispersion characteristics of these three structures are shown in Figure 16. It can be seen that the regions where the 4-bay structure has a much higher STL, at about 350 and $850 \mathrm{~Hz}$, correspond to a region where there are no cut-on frequencies and most of the dispersion curves around these two frequencies are above the corresponding acoustic wave. Conversely the dips in the STL at around 200, 630 and $1250 \mathrm{~Hz}$, correspond to the cut-on of several waves which rapidly approach the acoustic wavenumber. In fact, for the 4-bay structure, each cluster of waves consists of 8 new waves, which is the number of identical face plates (see also [14]). The 20-bay structure has many waves that cut on but these do not approach the acoustic wavenumber until higher frequencies.

When considering the 10-bay structure, which has the worst STL, it can be seen that the reason this structure has a much smaller $R_{w}$ is due to its relatively low STL between 800 and $1600 \mathrm{~Hz}$. From the dispersion curves in Figure 16, it can be seen that there are many waves in this region with wavenumbers that approach the acoustic wavenumber. 


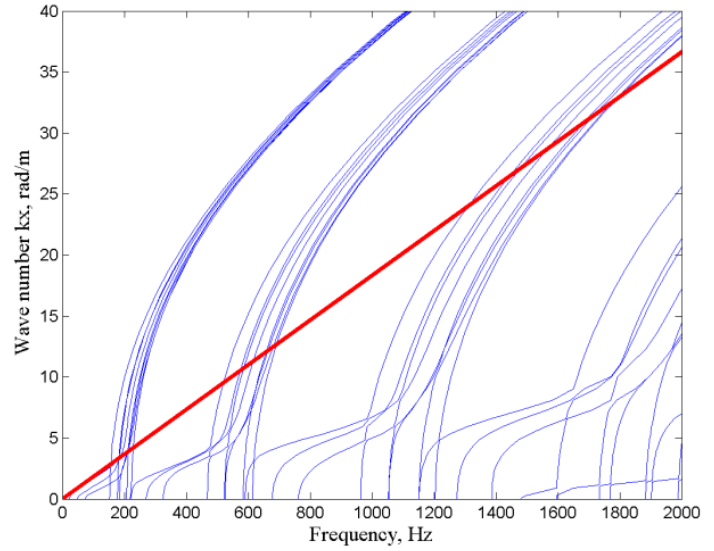

(a)

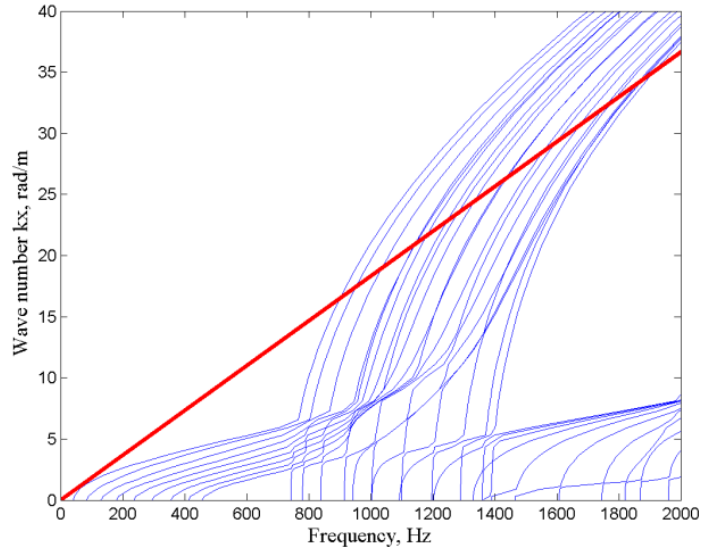

(b)

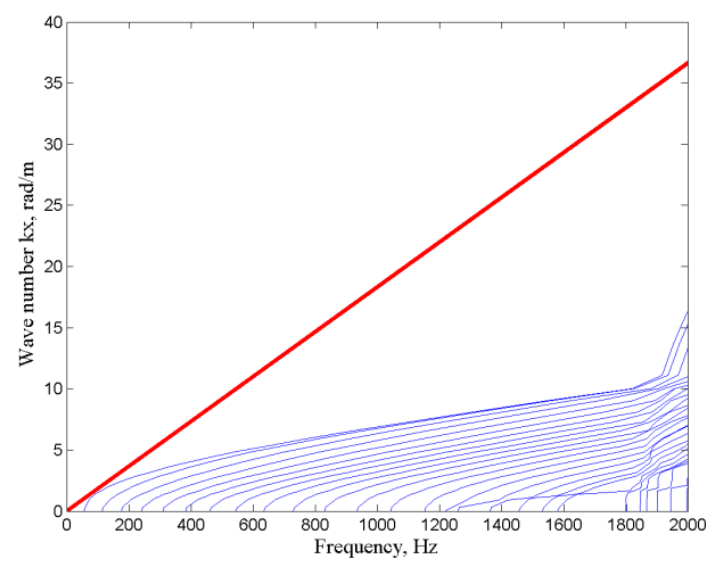

(c)

Figure 16 Dispersion characteristics of rectangular rib structures with bays of 4, 10 and 20. (a) 4 bays,

(b) 10 bays and (c) 20 bays

\subsection{Regular triangular rib extruded panels}

Similar to the investigation for the rectangular stiffened structure, the weighted STL and stiffness of structures with triangular stiffening ribs are investigated for different numbers of bays. A total of 12 cases are considered with between 4 and 15 bays. Examples are shown in Figure 17. The results are shown in Figure 18. Unlike the rectangular cases studied above, all the triangular cases studied have a larger stiffness than the reference panel. The masses of the triangular rib plates with 10 or more bays are higher than that of the reference panel. Similar to the rectangular stiffened plates, with the increase of the number of bays, the weighted STL first decreases, reaching a minimum for the 10-bay case, and then increases with further increases in the number of bays.

Compared with $R_{\mathrm{w}}$ in Figure 18(a), $R_{A 2}$ shown in Figure 18(b) is distributed slightly differently. Firstly, $R_{\mathrm{A} 2}$ is always above the mass law adjustment of $R_{\mathrm{A2}, 0}$. Secondly, the minimum value of $R_{\mathrm{A} 2}$ is for the 8 bay panel rather than the 10 bay panel. Thirdly, for both the 5 and 14 bay panels $R_{\mathrm{w}}$ is similar at around $28.5 \mathrm{~dB}$, while $R_{\mathrm{A} 2}$ is $23.5 \mathrm{~dB}$ for the 5 bay panel and $29.3 \mathrm{~dB}$ for the 14 bay one, which means the 14 bay extruded panel has much better sound insulation for this source spectrum.

Detailed results are presented for three cases. These are the case with minimum $R_{\mathrm{w}}$, with 10 bays, and two other structures with 5 bays and 14 bays which both have weighted STL of about $28.5 \mathrm{~dB}$. The details of the three structures are shown in Table 2. 


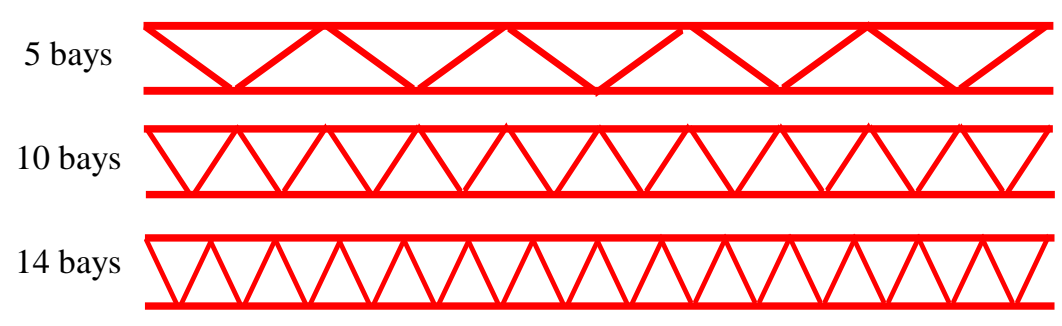

Figure 17 Examples of triangular rib structures with 5, 10 and 14 bays

The frequency-dependent STL and dispersion characteristics of these three particular cases are given in Figure 19 and Figure 20. The STL of the 5 bay case is lower than that of the 14 bay panel below $400 \mathrm{~Hz}$ and in the 630 1250 Hz frequency bands, while it is higher in the remaining frequency bands. The 10 bay structure has much lower STL between 1000 1600 Hz. This can be explained by the dispersion curves in Figure 20(b). Above $1000 \mathrm{~Hz}$ there are many waves with wavenumbers just below the acoustic wavenumber, which is similar to the case of the 10 bay rectangular rib panel in Figure 16(b) in the range 800-1600 Hz. Similarly the 14 bay case has many such waves at $2 \mathrm{kHz}$ where the STL drops. The clusters of waves seen for the rectangular stiffened panels are again found here although there are also waves associated with the diagonal stiffeners. It can also be noted from Figure 20 that the cut-on frequency of the first waves occurs around 250-400 Hz. This causes the STL to be stiffness-controlled below this frequency. If the panel width is increased these cut-on frequencies will be reduced, lowering the weighted STL, see Appendix B.

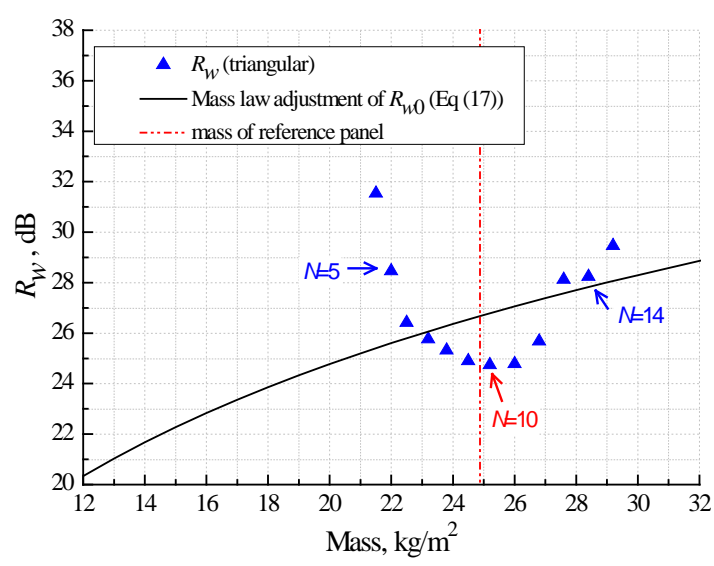

(a)

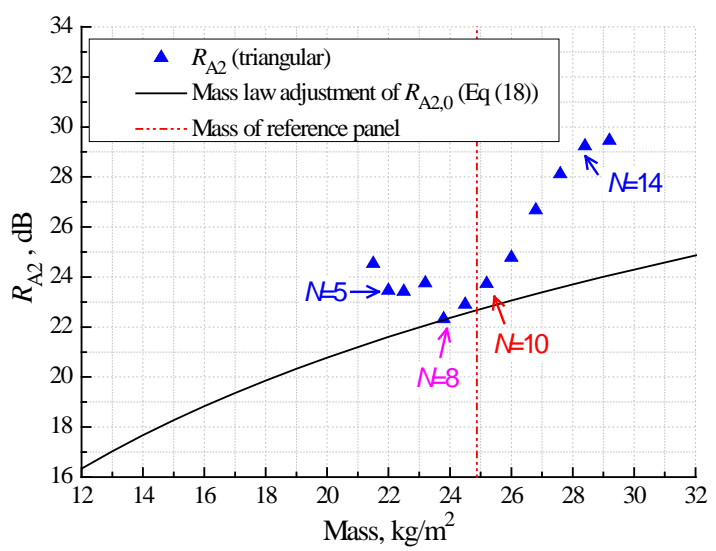

(b)

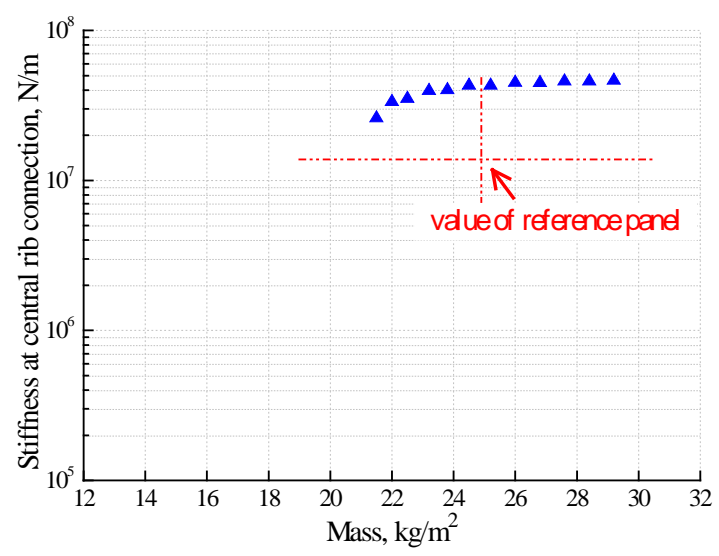


(c)

Figure 18 Weighted STL and stiffness of triangular rib structures. (a) $R_{w}$, (b) $R_{A 2}$ and (c) stiffness

Table 2 Details of triangular rib structure with 5, 10 and 14 bays

\begin{tabular}{|c|c|c|c|c|c|}
\hline $\begin{array}{c}\text { Number of Bays } \\
(N)\end{array}$ & $\begin{array}{c}\text { Mass per unit } \\
\text { area }\left(\mathrm{kg} / \mathrm{m}^{2}\right)\end{array}$ & $\begin{array}{c}\text { Stiffness } \\
(\mathrm{N} / \mathrm{m})\end{array}$ & $\begin{array}{c}\text { First cut-on } \\
\text { frequency }(\mathrm{Hz})\end{array}$ & $R_{w}(\mathrm{~dB})$ & $R_{\mathrm{A} 2}(\mathrm{~dB})$ \\
\hline 5 & 22.0 & $3.34 \times 10^{7}$ & 251 & 28.5 & 23.5 \\
\hline 10 & 25.2 & $4.30 \times 10^{7}$ & 403 & 24.7 & 23.7 \\
\hline 14 & 28.4 & $4.58 \times 10^{7}$ & 385 & 28.3 & 29.3 \\
\hline Reference panel & 24.9 & $1.38 \times 10^{7}$ & 137 & 26.9 & 22.7 \\
\hline
\end{tabular}

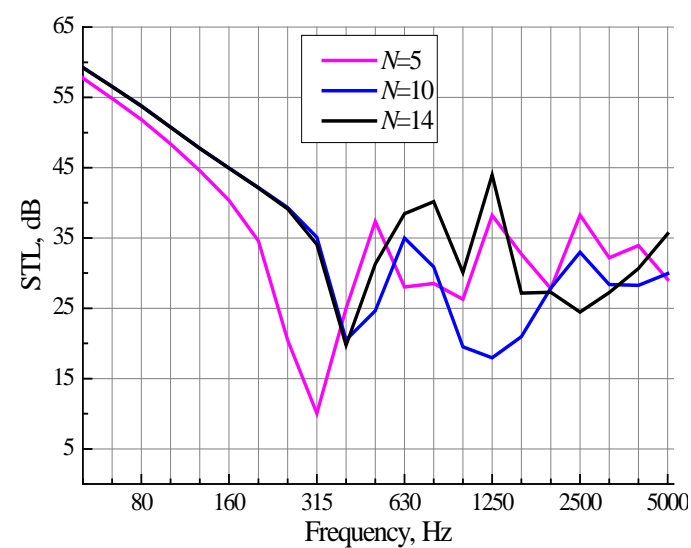

(a)

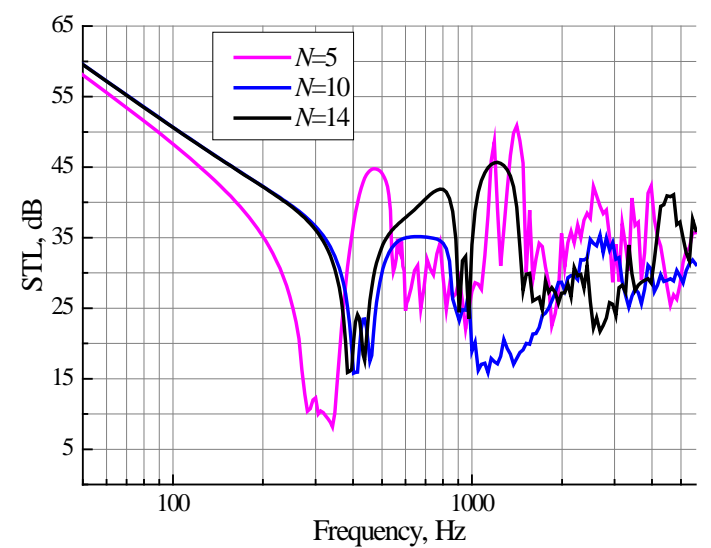

(b)

Figure 19 Frequency STL of triangular rib structures with 5, 10 and 14 bays. (a) one-third octave, (b) narrow band 


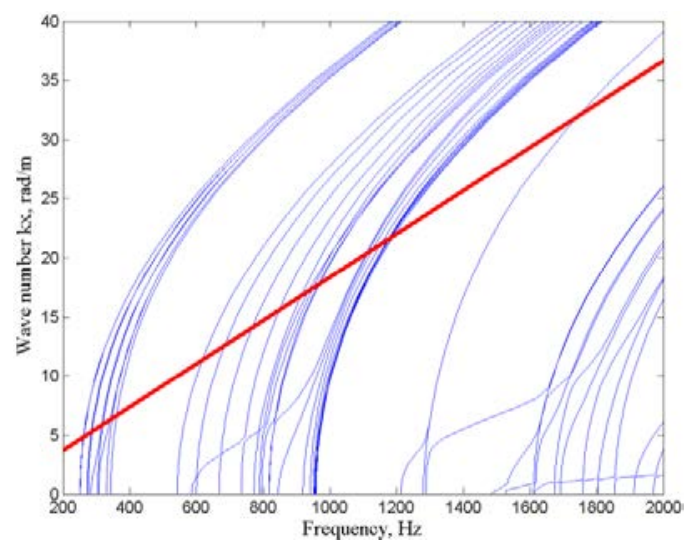

(a)

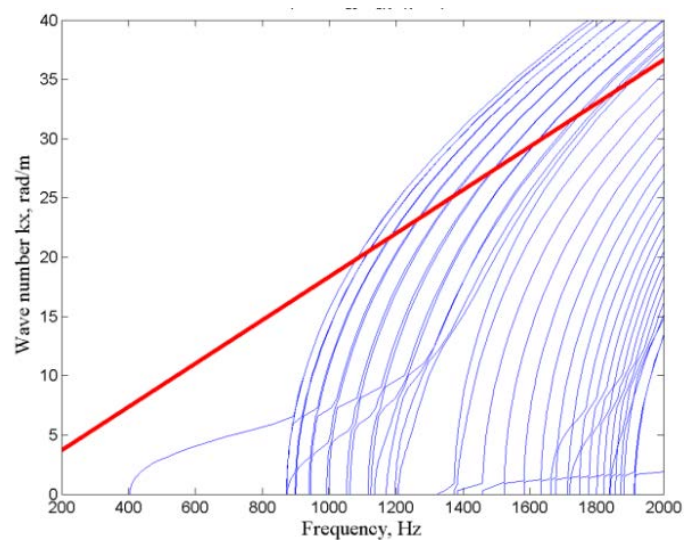

(b)

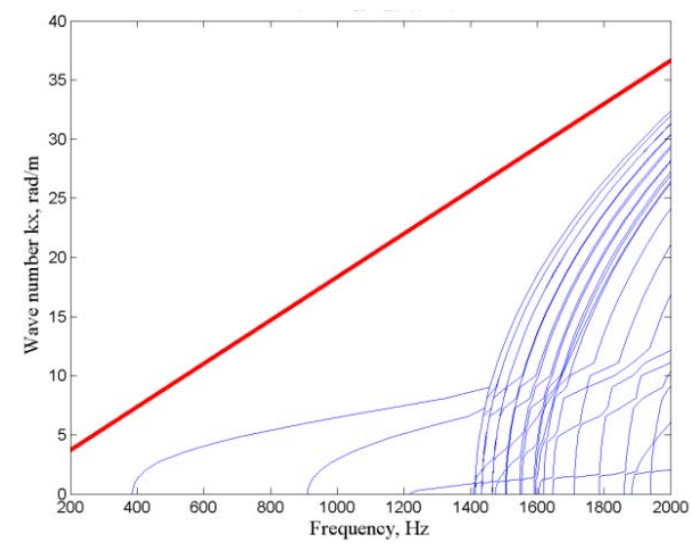

(c)

Figure 20 Dispersion characteristics of triangular rib structures with 5, 10 and 14 bays. (a) 5 bays, (b) 10 bays and (c) 14 bays

\subsection{Regular trapezium rib extruded panel}

In this section, trapezoidal geometry is considered, as shown in Figure 21. The trapezoidal reinforcement can be defined by two parameters, the number of bays and the inclination angle. The total width of the section is again fixed to $1 \mathrm{~m}$, and different numbers of bays and different inclination angles are studied. The specific cases studied are listed in Table 3.

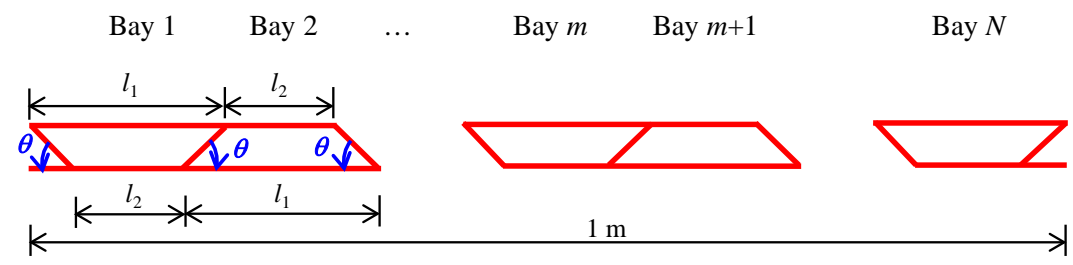

Figure 21 Diagram of regular trapezium rib extruded panel

Table 3 Summary of trapezium condition investigation

\begin{tabular}{|c|c|c|c|}
\hline Cases & Number of bays & Inclination studied $\left(^{\circ}\right)$ & Number of cases \\
\hline T1 & 5 & $25,30,35, \ldots 90$ & 14 \\
\hline T2 & 7 & $35,40,45, \ldots 90$ & 12 \\
\hline T3 & 9 & $40,45,50, \ldots 90$ & 11 \\
\hline
\end{tabular}

The number of bays considered, $N$, is set to 5,7 , and 9 . For each of these numbers, different 
inclination angles are investigated from the minimum inclination angle of the structure to $90^{\circ}$ in steps of $5^{\circ}$. The minimum inclinations are $25^{\circ}, 35^{\circ}$ and $40^{\circ}$ respectively for the structures with 5,7 and 9 bays; these configurations are close to triangular arrangements. In each case $90^{\circ}$ corresponds to a rectangular rib configuration.

Figure 22 gives the weighted STL and panel stiffness for the 37 cases of Table 3 . The green rectangle, the pink hexagon, and the dark yellow pentagon represent the cases with 5, 7 and 9 bays, respectively. For each number of bays, the smaller the inclination angle is, the larger the mass becomes.

As shown in Figure 22, firstly, all the cases studied have much smaller mass than the reference panel, as this additionally has vertical stiffeners as well as inclined ones (see Figure 6). In most cases $R_{w}$ and $R_{\mathrm{A} 2}$ are above the mass line, particularly for small inclination angles. Compared with $R_{\mathrm{W}}$ in Figure 22(a), the trend of $R_{\mathrm{A} 2}$ is similar. However, $R_{\mathrm{A} 2}$ for $N=7$ is not so sensitive to the mass as $R_{\mathrm{w}}$ in Figure 22(a). The stiffness also increases with reducing inclination angle and there are two cases, namely $N=5, \theta=25^{\circ}$ and $N=9, \theta=40^{\circ}$, which have a higher stiffness than the reference panel. The case $N=5, \theta=25^{\circ}$ gives the best results, since it has a $6 \mathrm{~dB}$ higher $R_{\mathrm{w}}$ than the reference panel, with a smaller mass and slightly higher stiffness. The numbers of bays also affects the STL. The weighted STL of panel with 5 bays is greater than that of panel with 7 bays, which is greater than that of those with 9 bays. Cases with 11, 13 and 15 bays have also been tested (not shown here) but they all had weighted STL lower than the mass line. 


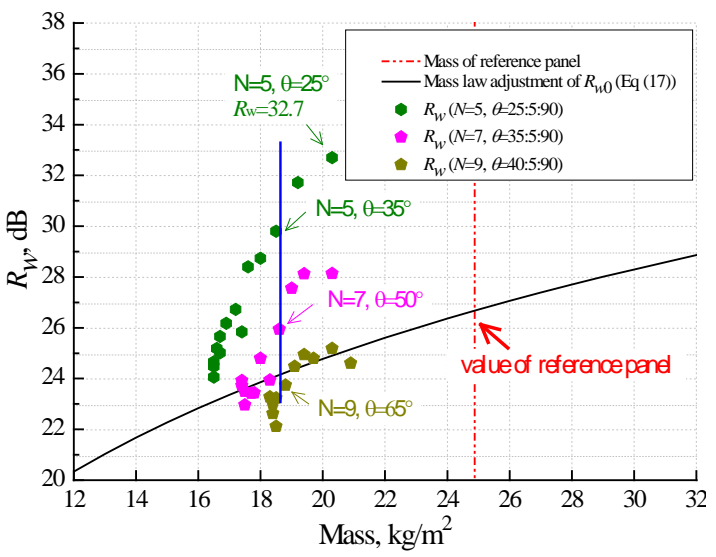

(a)

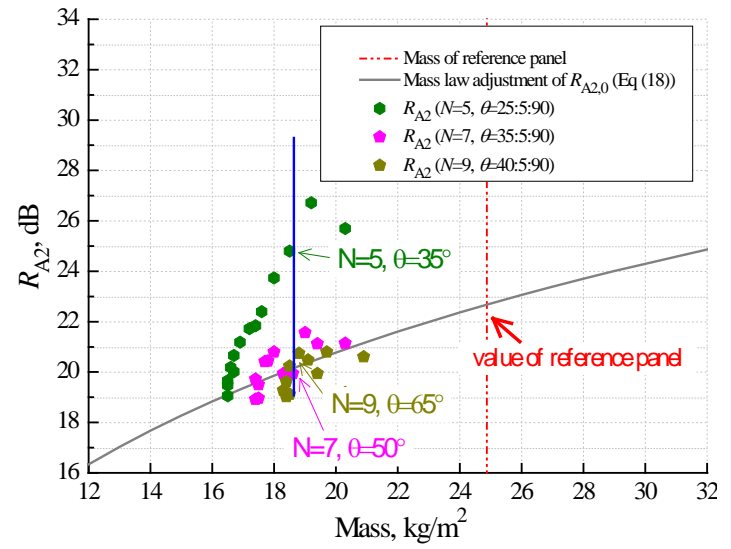

(b)

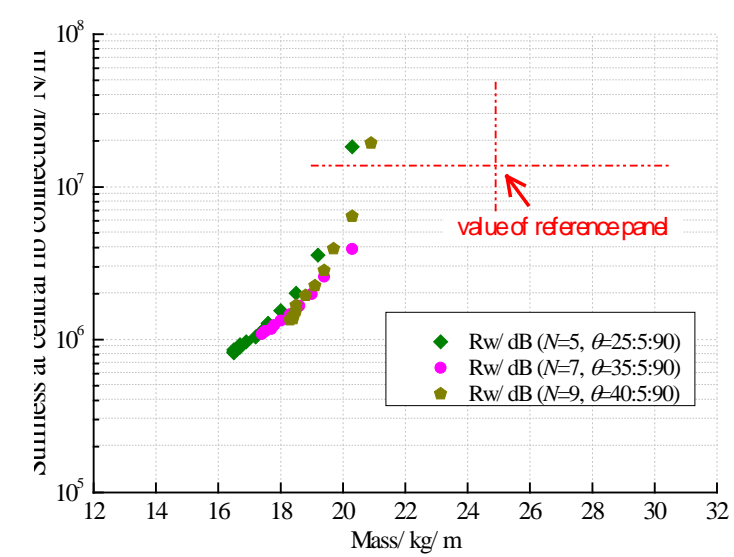

(c)

Figure 22 Weighted STL and stiffness of trapezoidal rib structures. (a) $R_{w}$, (b) $R_{A 2}$ and (c) stiffness

Results from three cases with similar mass are compared in terms of their frequency-dependent STL. As indicated in Figure 22, three structures are chosen around $19 \mathrm{~kg} / \mathrm{m}^{2}$. Their specific cross-sections are shown in Figure 23, and their mass and weighted STL are given in Table 4. The corresponding frequency-dependent STL and dispersion curves are shown in Figure 24 and Figure 25 respectively.

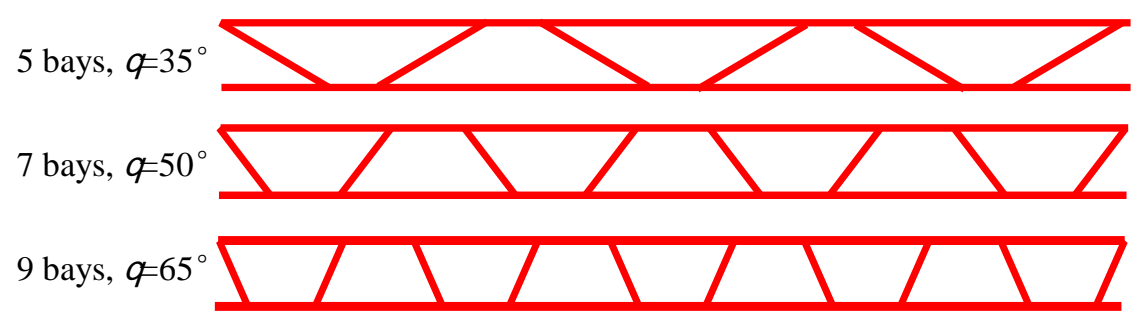

Figure 23 Examples of trapezium rib structures (see Table 4) 
Table 4 Details of chosen trapezoidal rib structures with 5, 7 and 9 bays

\begin{tabular}{|c|c|c|c|c|c|c|}
\hline $\begin{array}{c}\text { No. of bays } \\
(N)\end{array}$ & $\begin{array}{c}\text { Inclination of } \\
\text { ribs } \theta\left(^{\circ}\right)\end{array}$ & $\begin{array}{c}\text { Mass per unit } \\
\text { area }\left(\mathrm{kg} / \mathrm{m}^{2}\right)\end{array}$ & $\begin{array}{c}\text { Stiffness } \\
(\mathrm{N} / \mathrm{m})\end{array}$ & $\begin{array}{c}\text { First cut-on } \\
\text { frequency }(\mathrm{Hz})\end{array}$ & $\begin{array}{c}R_{w} \\
(\mathrm{~dB})\end{array}$ & $\begin{array}{c}R_{\mathrm{A} 2} \\
(\mathrm{~dB})\end{array}$ \\
\hline 5 & 35 & 18.5 & $2.01 \times 10^{6}$ & 48 & 29.8 & 24.8 \\
\hline 7 & 50 & 18.6 & $1.67 \times 10^{6}$ & 51 & 25.9 & 19.9 \\
\hline 9 & 65 & 18.8 & $1.95 \times 10^{6}$ & 49 & 23.7 & 20.7 \\
\hline \multicolumn{2}{|r|}{ Reference panel } & 24.9 & $1.38 \times 10^{7}$ & 137 & 26.9 & 22.7 \\
\hline
\end{tabular}

As can be seen from Figure 24, the largest differences between the STL of the three trapezoidal structures with similar mass occurs between the 100 and $1000 \mathrm{~Hz}$ frequency bands. The case with only five bays has the greatest STL in this region. All three have a similar first cut-on frequency in the $50 \mathrm{~Hz}$ band as they have similar panel stiffnesses. These results can be further explained by inspecting the dispersion characteristics of each structure, shown in Figure 25.

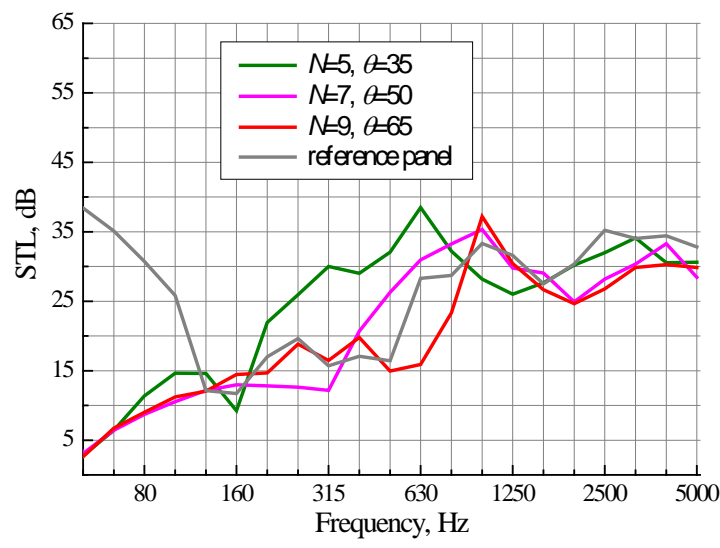

(a)

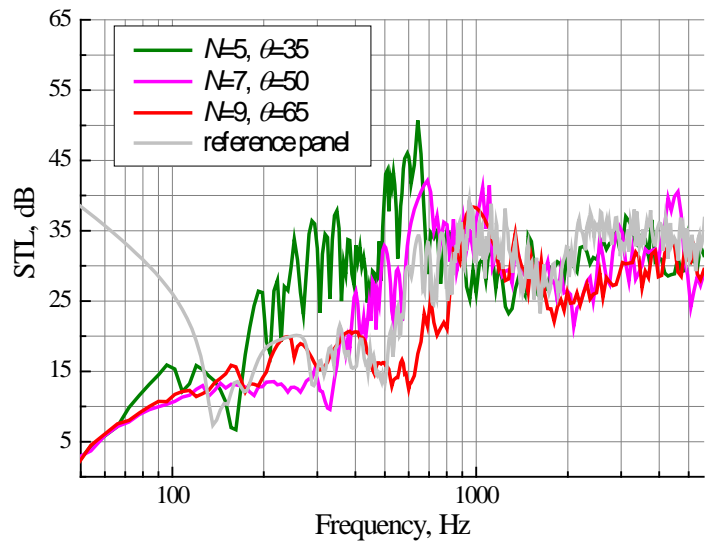

(b)

Figure 24 STL of example trapezoidal rib structures with 5, 7 and 9 bays. (a) one-third octave, (b) narrow band 


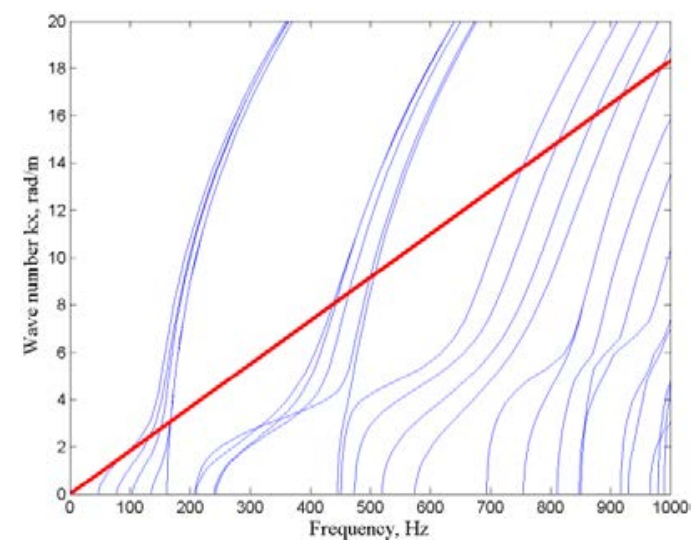

(a)

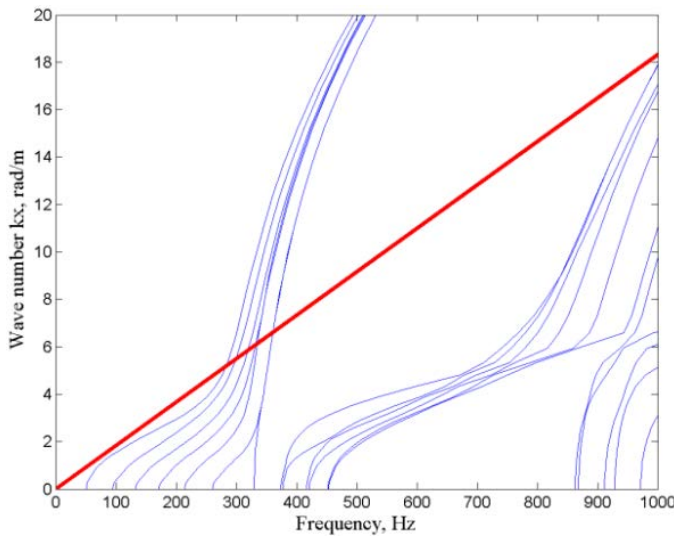

(b)

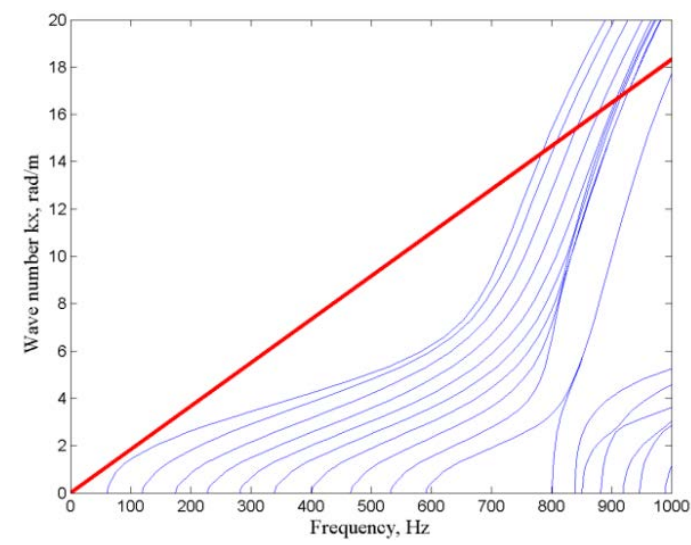

(c)

Figure 25 Dispersion characteristics of trapezoidal rib structures with bays of 5,7 and 9 . (a) $N=5$,

$$
\theta=35^{\circ} \text {, (b) } N=7, \theta=50^{\circ} \text { and (c) } N=9, \theta=65^{\circ}
$$

The dispersion curves in Figure 25 show clusters of waves, with the same number of waves in each cluster as the number of bays (see also [14]). Moreover the case with $N=5$ has more waves above the corresponding wavenumber of sound in air, which results in improved STL. The STL usually has high values in frequency bands in which there is no cut-on frequency and no waves just below the wavenumber in air. Nevertheless, it is not always possible to judge qualitative performance from only the dispersion plots.

\subsection{Discussion}

In the regular rib cases studied above, there are three cases which have much smaller mass, but larger stiffness and higher $R_{w}$ than the reference panel. As shown in Table 5, they are 4 and 5 bays regular triangular rib panel, and 5 bays trapezium rib panel with inclination angle $\theta=25^{\circ}$. The STL is plotted against frequency in Figure 26. Of these, the trapezium rib panel has the highest weighted $\mathrm{STL}$. The improvement relative to the reference panel ranges from 2 to $6 \mathrm{~dB}$ for $R_{w}$ and 1 to $3 \mathrm{~dB}$ for $R_{\mathrm{A} 2}$. It is clear from these results that there are still some frequency bands with low STL; these could possibly be improved by combining these panels with added damping. 
Table 5 Cases better than the reference panel

\begin{tabular}{|c|c|c|c|c|c|}
\hline Rib type & $\begin{array}{c}\text { No. of bays } \\
(N)\end{array}$ & $\begin{array}{c}\text { Mass per unit area } \\
\left(\mathrm{kg} / \mathrm{m}^{2}\right)\end{array}$ & $\begin{array}{c}\text { Stiffness } \\
(\mathrm{N} / \mathrm{m})\end{array}$ & $\begin{array}{c}R_{w} \\
(\mathrm{~dB})\end{array}$ & $\begin{array}{c}R_{\mathrm{A} 2} \\
(\mathrm{~dB})\end{array}$ \\
\hline \multirow{2}{*}{ triangular rib } & 4 & 21.5 & $2.60 \times 10^{7}$ & 31.5 & 24.5 \\
\cline { 2 - 6 } & 5 & 22.0 & $3.34 \times 10^{7}$ & 28.5 & 23.5 \\
\hline trapezium rib & $5\left(\right.$ Inclination $\left.: 25^{\circ}\right)$ & 20.3 & $1.83 \times 10^{7}$ & 32.7 & 25.7 \\
\hline \multicolumn{2}{|r|}{ Reference panel } & 24.9 & $1.38 \times 10^{7}$ & 26.9 & 22.9 \\
\hline
\end{tabular}

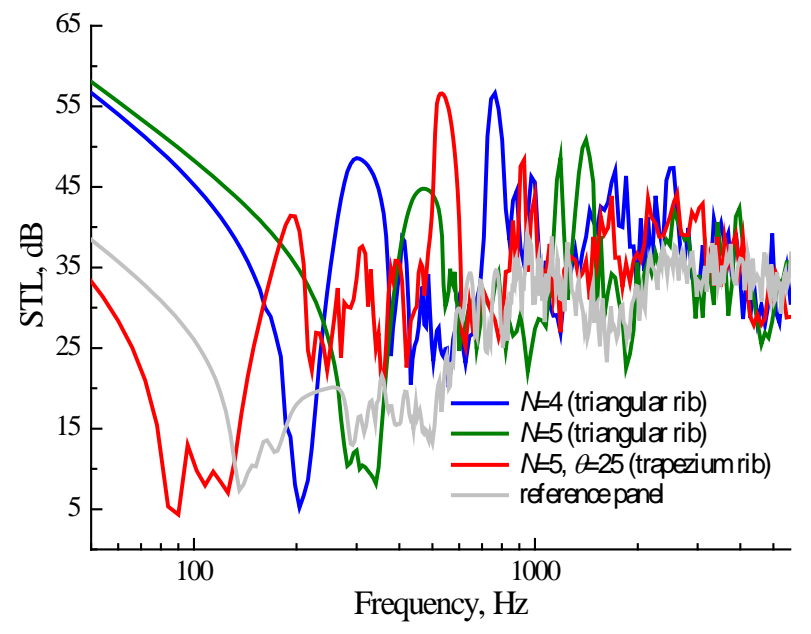

Figure 26 STL of reference panel and three better cases

For all the parameters investigated above, the boundaries are clamped and the width of the model is kept as $1 \mathrm{~m}$. The effect of varying the boundary condition and the model width is investigated for selected cases in Appendix B. This shows that the main influence of both the boundary conditions and the width is limited to the low frequency region, especially near and below the first cut-on frequency. The trapezium rib panel is relatively unaffected by the width whereas the benefit of the triangular rib panel is reduced when the panel width is increased.

\section{Conclusions}

The STL of a practical extruded panel has been investigated using the WFE-WBE method and a parameter study has been carried out to compare different thickness and regular stiffening arrangements.

The damping loss factor has been investigated experimentally for positions on the two sides of the panel. From calculations of STL it is shown that the rubber layer also gives an improvement in the STL of the panel, especially at frequencies above about $1250 \mathrm{~Hz}$, where the improvement reaches about $10 \mathrm{~dB}$ at the dips of the STL. Most of this improvement is due to its added mass since the extra mass of the thick rubber layer is roughly the same as of the bare face structure.

Changing the thickness of the incident or transmitted face plates to half their original values, it was found that the weighted STL of the structure did not decrease. However, the stiffness of the panel was reduced to just over half of its original value. Changing the overall thickness of the structure appeared the least promising of the parameter changes involving the thickness.

Compared with the reference panel, among the regular rib cases studied only three cases are found which have smaller mass but larger stiffness and higher $R_{w}$ at the same time. They are a 
regular triangular rib panel with 4 and 5 bays in a $1 \mathrm{~m}$ width, and a trapezium rib panel with 5 bays and inclination angle $\theta=25^{\circ}$ which is quite similar to the triangular rib panel. It can be concluded that, considering the practical stiffness of the structure, a triangular rib panel gives the best results for the given boundary conditions and based on the choice of rib thickness and overall panel width. The results show that, the number of rib plates should be considered carefully to avoid worst cases.

Among the different structures studied, the structures with better STL usually have a small number of waves with wavenumber below the acoustic wavenumber, especially in the region just below the acoustic wavenumber and more above the acoustic wavenumber. The relative results presented here also provide a method of systematic evaluation and practical analysis for combined low noise and lightweight design of extruded panels. A fuller optimization could consider the thickness of the strips and of the panel to be variables simultaneously with the geometrical arrangement, and this should also be based on a more realistic panel width. Such a study would require considerable computational resources.

\section{Acknowledgements}

The simulation results presented in this paper have been obtained using the software WANDS (Wave-Number-Domain FE-BE Software for Structures and Fluids). The present work is supported by the National Natural Science Foundation of China (Nos. U1434201, 51475390) and the Research Foundation of the State Key Laboratory of Traction Power of China (No. 2015TPL_T08). We are also grateful for the funding of China Scholarship Council (CSC) which supported Yumei Zhang's visiting study at the University of Southampton.

\section{References}

[1] D. Thompson, Railway Noise and Vibration, Mechanisms, Modelling and Means of Control Oxford: Elsevier Science, 1st Edition 2009.

[2] X.S. Jin, Key problems faced in high-speed train operation, Journal of Zhejiang University Science A, vol. 15, pp. 936-945, 2014.

[3] Y. Zhang, X. Xiao, D. Thompson, G. Squicciarini, Z. Wen, Z. Li, and Y. Wu, Sound transmission loss of windows on high speed trains, Journal of Physics: Conference Series, vol. 744, pp. 012141, 2016.

[4] J. Zhang, X. Xiao, X. Sheng, C. Zhang, R. Wang, and X. Jin, SEA and contribution analysis for interior noise of a high speed train, Applied Acoustics, vol. 112, pp. 158-170, 2016.

[5] N.J. Shaw. The Prediction of Railway Vehicle Internal Noise Using Statistical Energy Analysis Techniques, MSc Thesis, Heriot-Watt University, Edinburgh, 1990.

[6] L. Ji, X. Sheng, X. Xiao, Z. Wen, and X. Jin, A review of mid-frequency vibro-acoustic modelling for high-speed train extruded aluminium panels as well as the most recent developments in hybrid modelling techniques, Journal of Modern Transportation, vol. 23, pp. 159-168, 2015.

[7] G. Xie, D.J. Thompson and C.J.C. Jones. A modelling approach for the vibroacoustic behaviour of aluminium extrusions used in railway vehicles. Journal of Sound and Vibration, 2006, (293): 921-932.

[8] U. Orrenius, Y.-Y. Pang, S. Finnveden, B. Stegemann, Acoustic modelling of extruded profiles 
for railway cars, Proc. NOVEM 2005.

[9] B. Stegemann, Development and validation of a vibro-acoustic model of a metro rail car using Statistical Energy Analysis (SEA), MSc thesis of Chalmers University of Technology, 2002.

[10] R.S. Langley, P. Bremner. A hybrid method for the vibration analysis of complex structural-acoustic systems. Journal of the Acoustical Society of America, 1999, 105(3): 1657-1671

[11] V. Cotoni, R.S. Langley, P.J. Shorter. A statistical energy analysis subsystem formulation using finite element and periodic structure theory. Journal of Sound and Vibration, 2008 (318): 1077-1108.

[12] T. Kohrs, B. Petersson, Wave propagation in light weight profiles with truss-like cores: Wavenumber content, forced response and influence of periodicity perturbations. Journal of sound and vibration, 2007, 304(3): 691-721.

[13] T. Kohrs, B. Petersson, Wave beaming and wave propagation in light weight plates with truss-like cores. Journal of Sound and Vibration 321:137-165, 2009.

[14] T. Kohrs, Wave propagation in light weight plates with truss-like cores, PhD Thesis, TU Berlin, 2008.

[15] U. Orrenius, H. Liu, A. Wareing, S. Finnveden, V. Cotoni, Wave modelling in predictive vibro-acoustics: applications to rail vehicles and aircraft. Wave Motion 51:635-649, 2014.

[16] J. Wang, T. J. Lu, J. Woodhouse, R. S. Langley, and J. Evans, Sound transmission through lightweight double-leaf partitions: theoretical modelling, Journal of Sound and Vibration, vol. 286, pp. 817-847, 2005.

[17] T. Lu, F. Xin, Vibro-Acoustics of Lightweight Sandwich Structures, Beijing, Science Press, 2014.

[18] I. Prasetiyo, Investigation of sound transmission in lightweight structures using a waveguide finite element boundary element approach, PhD thesis, University of Southampton, 2012.

[19] C. M. Nilsson, A. N. Thite, C. J. C. Jones and D. J. Thompson, Estimation of sound transmission through extruded panels using a coupled waveguide finite element-boundary element method, Notes on Numerical Fluid Mechanics and Multidisciplinary Design 99, 306-312, 2008.

[20] H. Kim, J. Ryue, D. J. Thompson, and A. D. Müller, Prediction of radiation ratio and sound transmission of complex extruded panel using wavenumber domain finite element and boundary element methods, Journal of Physics: Conference Series, vol. 744, p. 012144, 2016.

[21] C. M. Nilsson, J. Ryue, and C. J. C. Jones, Manual for WANDS 2.2 Wavenumber domain software for solids and fluids, University of Southampton, 2010.

[22] C. M. Nilsson, J. Ryue, and C. J. C. Jones, Theory manual for WANDS 2.1 Wave-number-domain FE-BE software for structures and fluids, University of Southampton, 2010.

[23] ISO 717-1:2013. Acoustics - Rating of sound insulation in buildings and of building elements - Part 1: Airborne sound insulation.

[24] D. J. Ewins, Modal Testing Theory and Practice. Letchworth: Research Studies Press, 1984.

[25] F. Fahy and D. Thompson, Fundamentals of Sound and Vibration, Second Edition: Boca Raton: CRC Press, 2015. 


\section{Appendix A. Measurement of damping loss factor}

The damping loss factor is determined from measured frequency response functions using two methods. The conventional low frequency method is to determine the modal damping from the bandwidth of each resonance peak, for example using the Nyquist circle fitting method [24]. However, at high frequencies where the modal density and modal overlap increase, an energy method can be used to calculate the loss factor in one-third octave bands [25]. The results from these two methods are compared for one measurement point before using the energy method for the remaining points.

\section{A.1 Experimental setup}

To obtain the damping loss factor, the frequency response functions of the structure are required. To measure the Frequency Response Function (FRF) of this extruded panel, it was first freely suspended on elastic ropes and the point mobility of each bay was measured by using an instrumented impact hammer and an accelerometer. As shown in Figure A.1, the measurement positions for the point mobility are located at about $1 / 5$ of panel length and mid-way across the width of each bay, see points P1-1 to P1-6 in Figure A.1(a) and P2-1 to P2-8 in Figure A.1(b).

In addition, transfer mobilities were measured in each bay by keeping the accelerometer fixed and varying the impact point along the bay. A total of 50 excitation points were used in each bay, randomly distributed over the bay to obtain the spatial average.

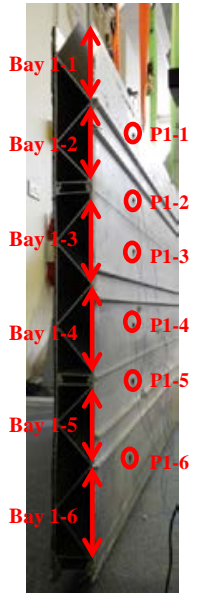

(a)

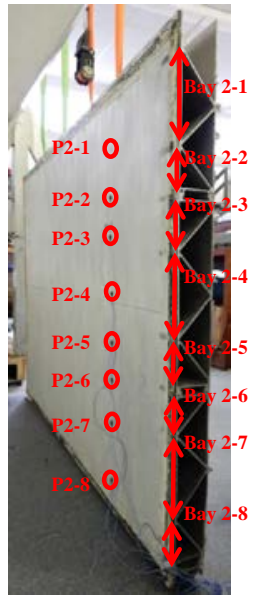

(b)

Figure A.1 Schematic view of point mobility measurement of each bay. (a) bays on bare face plate, (b) bays on face plate with added rubber layer

\section{A.2 Result of damping loss factor}

The damping loss factor is estimated from the energy method [25]. From the definition of the loss factor, assuming there are many modes in a frequency band, the dissipated power can be estimated from the product of the loss factor $\eta$, angular frequency $\omega$, the mass $m$ and the spatially-averaged mean square velocity $\left\langle\overline{v^{2}}\right\rangle$ as:

$$
W_{\text {diss }}=\eta \omega m\left\langle\overline{v^{2}}\right\rangle
$$


Equating this to the input power and normalising to a unit mean square input force, the loss factor can be written as:

$$
\eta=\frac{\operatorname{Re}\left(Y_{i n}\right)}{m \omega\left\langle|Y|_{t}^{2}\right\rangle}
$$

where $Y_{\text {in }}$ is the driving point mobility and $\left\langle|Y|_{t}^{2}\right\rangle$ is the spatially-averaged squared transfer mobility. Both quantities are measured using the impact hammer to excite the structure.

The damping loss factor calculated from the energy method is first compared with results from the Nyquist circle method [24] for a single excitation point. Taking point P1-3 as an example (see Figure 1(a)), the damping loss factor results are given in Figure A.2. It can be seen that the damping loss factor calculated through the two methods has the same trend, with good agreement above 800 $\mathrm{Hz}$, and especially above $3000 \mathrm{~Hz}$. Due to the amount of effort required to use the Nyquist circle method, only the energy method is used for other locations, the results of which are given in Figures 2 and 3.

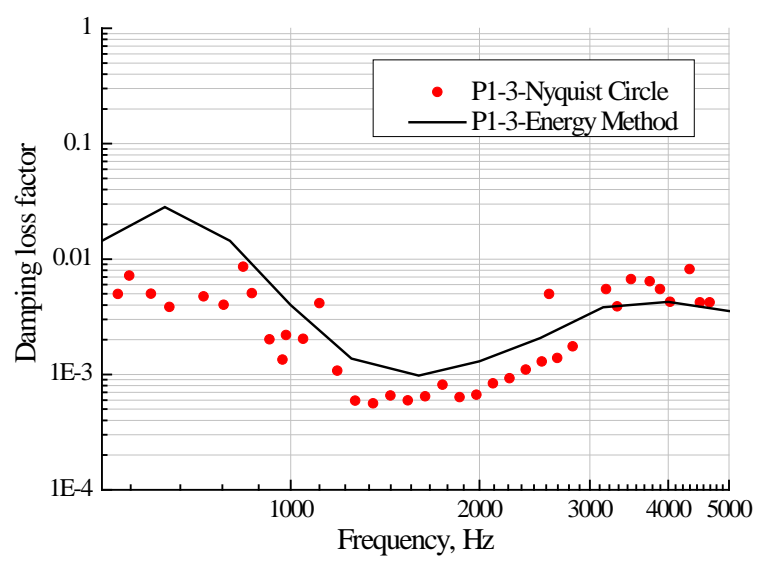

Figure A.2 Damping loss factor at measurement position P1-3

\section{Appendix B. Influence of boundary conditions and panel width on}

\section{STL}

In all the results presented in the paper, the boundaries are clamped at both edges and the width of the model is limited to $1 \mathrm{~m}$. Here, selected results are presented to investigate whether the results are affected by these restrictions.

\section{B.1 Influence of boundary conditions on STL}

In this section, two other boundary conditions are considered for the bare reference panel for comparison with the clamped boundaries considered in the paper. They are simply supported and free boundary conditions.

Table B.1 gives the first cut-on frequency, and the weighted diffuse field STL. It can be seen that the values of $R_{\mathrm{w}}$ obtained for different boundary condition are within about $1.5 \mathrm{~dB}$ of one another. The spectral characteristics of the diffuse STL are shown in Figure B.1. It can be seen that 
the effect of the boundary condition is mainly restricted to low frequencies, especially near and below the first cut-on frequency.

Table B.1 Influence of boundary conditions on STL of reference panel

\begin{tabular}{|c|c|c|c|}
\hline Boundary condition & First cut-on frequency $(\mathrm{Hz})$ & $R_{w}(\mathrm{~dB})$ & $R_{\mathrm{A} 2}(\mathrm{~dB})$ \\
\hline Clamped & 138 & 26.9 & 22.9 \\
\hline Simply supported & 90 & 26.1 & 21.1 \\
\hline Free & 0 & 27.3 & 23.3 \\
\hline
\end{tabular}

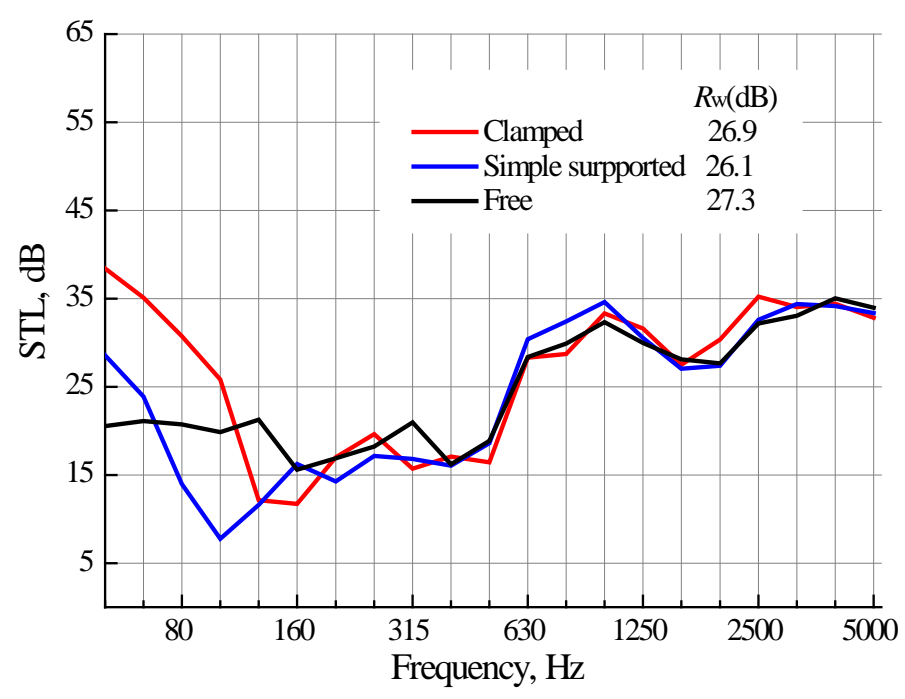

Figure B.1 Influence of boundary conditions on diffuse STL of reference panel.

\section{B.2 Influence of panel width on STL}

In order to investigate the effect of the width of the structure on the STL, the results for the bare reference section, and the triangular rib panels with 5 bays and trapezium rib panels with 5 bays at the inclination of $25^{\circ}$ are studied for different widths. Again the diffuse field STL is considered.

The size effect of reference panel is firstly studied. Figure B.2 shows the sections of three different sizes which have widths $1.0 \mathrm{~m}, 1.72 \mathrm{~m}$ and $3.09 \mathrm{~m}$. The details are given in Table B.2 including the first cut-on frequency, mass per unit area and the weighted diffuse field STL. It can be seen that the values of $R_{\mathrm{w}}$ obtained for different widths are within about $1.5 \mathrm{~dB}$ of one another; especially when the width is enlarged from $1.72 \mathrm{~m}$ to $3.09 \mathrm{~m}$, the difference in $R_{\mathrm{w}}$ is only $0.6 \mathrm{~dB}$.

The spectral characteristics of the diffuse STL are shown in Figure B.3 for these three different widths. Similar to the influence of the boundary conditions on the STL, the effect of the width is also mainly restricted to low frequencies, especially near and below the first cut-on frequency.

Case 1-1 $\mathbb{\triangle} \backslash \triangle \nabla \mathbb{A}$

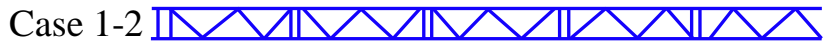

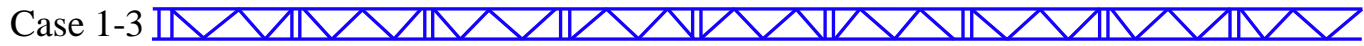

Figure B.2 Diagram of reference extruded panel in different widths 
Table B.2 Influence of width on STL of reference panel

\begin{tabular}{|c|c|c|c|c|c|}
\hline Cases & $\begin{array}{c}\text { Width } \\
(\mathrm{m})\end{array}$ & $\begin{array}{c}\text { First cut-on } \\
\text { frequency }(\mathrm{Hz})\end{array}$ & $\begin{array}{c}\text { Mass per unit area } \\
\left(\mathrm{kg} / \mathrm{m}^{2}\right)\end{array}$ & $R_{w}(\mathrm{~dB})$ & $R_{\mathrm{A} 2}(\mathrm{~dB})$ \\
\hline $1-1$ & 1.0 & 136 & 24.9 & 26.9 & 22.9 \\
\hline $1-2$ & 1.72 & 116 & 24.6 & 25.9 & 20.9 \\
\hline $1-3$ & 3.09 & 44 & 24.6 & 25.3 & 21.3 \\
\hline
\end{tabular}

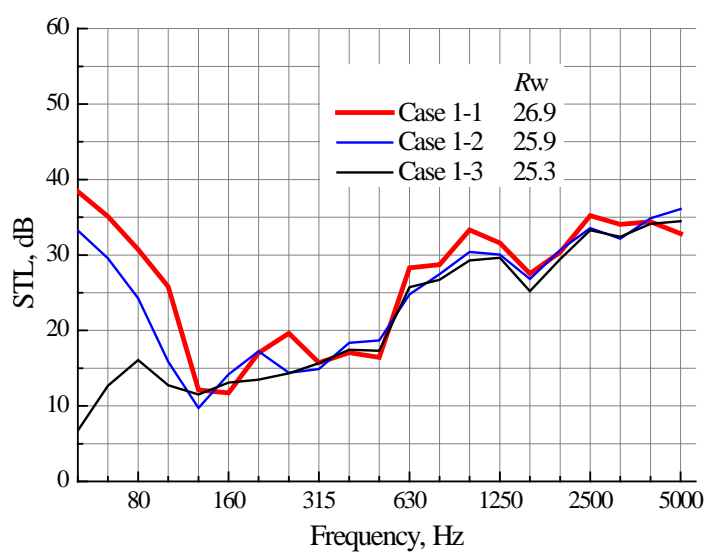

Figure B.3 Effect of width on diffuse field STL of reference panel.

Since, in the parameter study in Section 4, the 5 bay triangular rib panel and 5 bay trapezium rib panel with rib inclination of $25^{\circ}$ were found to give the best results for the $1 \mathrm{~m}$ width, the effect of the panel width is also studied for these two examples, as shown in Figure B.4 and Figure B.5 respectively. The cases considered are summarised in Table B.3 and Table B.4 including their width, number of bays, first cut-on frequency and weighted diffuse field STL.

For cases 2-1 2-3, it can be seen that as the width is increased the value of $R_{\mathrm{w}}$ decreases. This can also be explained by the spectral characteristics of the STL in Figure B.6. Similar to the result for the reference panel, the width mainly influences the STL near and below the first cut-on frequency. However, the values of $R_{\mathrm{w}}$ of the triangle rib plates are more sensitive to the width; the result reduces by $2.2 \mathrm{~dB}$ when it is increased from $1.0 \mathrm{~m}$ to $1.4 \mathrm{~m}$. This is mainly because the stiffness-controlled region of the STL occurs in the frequency bands considered for the weighted STL (100 3150 Hz).

For cases 3-1 3-3, it can be seen that when the width is increased from $0.71 \mathrm{~m}$ to $1 \mathrm{~m}$ the value of $R_{w}$ decreases. However, when the width is increased from $1.00 \mathrm{~m}$ to $1.34 \mathrm{~m}$, the $R_{\mathrm{w}}$ has almost no change. This can also be explained by the spectral characteristics of the diffuse field STL in Figure B.7. The width not only influences the STL near and below the first cut-on frequency but also the STL around $200 \mathrm{~Hz}$. However, the result for case 3-2 and 3-3 are not sensitive to width. This is mainly because the STL above the first cut-on frequency does not change much anymore when the width is larger than $1.0 \mathrm{~m}$ and the stiffness-controlled region of STL does not occur in the frequency bands considered for the weighted STL (100 3150 Hz), which is different from cases 2-2 and 2-3.

This also implies that, among the best cases studied and discussed in section 4, the 5 bay trapezium rib panel with rib inclination of $25^{\circ}$ is the best and most stable case, the weighted STL of which does not change much even if its width is enlarged, whereas the triangular rib cases are more sensitive to the width. 
Case 2-1 $\triangle \triangle \triangle$

Case 2-2

Case 2-3

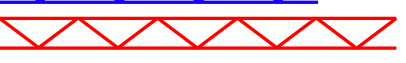

Figure B.4 Diagram of 5 bays in $1 \mathrm{~m}$ triangular extruded panel in different widths

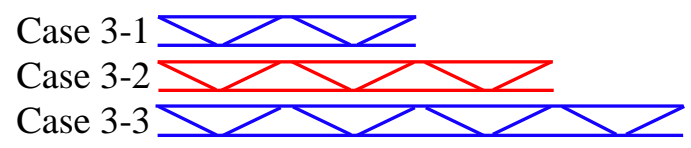

Figure B.5 Diagram of 5 bays in $1 \mathrm{~m}$ trapezium extruded panel (Inclination: 25) in different widths

Table B.3 Influence of width on STL of case 2-1 2-3

\begin{tabular}{|c|c|c|c|c|c|c|}
\hline cases & $\begin{array}{c}\text { width } \\
(\mathrm{m})\end{array}$ & $\begin{array}{c}\text { Number of } \\
\text { bays }(\mathrm{N})\end{array}$ & $\begin{array}{c}\text { First cut-on } \\
\text { frequency }(\mathrm{Hz})\end{array}$ & $\begin{array}{c}\text { Mass per unit area } \\
\left(\mathrm{kg} / \mathrm{m}^{2}\right)\end{array}$ & $R_{w}(\mathrm{~dB})$ & $R_{\mathrm{A} 2}(\mathrm{~dB})$ \\
\hline $2-1$ & 0.8 & 4 & 312 & & 30.1 & 24.1 \\
\hline $2-2$ & 1.0 & 5 & 282 & 22.0 & 28.5 & 23.5 \\
\hline $2-3$ & 1.4 & 7 & 204 & & 26.3 & 21.3 \\
\hline
\end{tabular}

Table B.4 Influence of width on STL of case 3-1 3-3

\begin{tabular}{|c|c|c|c|c|c|c|}
\hline cases & $\begin{array}{c}\text { width } \\
(\mathrm{m})\end{array}$ & $\begin{array}{c}\text { Number of } \\
\text { bays }(\mathrm{N})\end{array}$ & $\begin{array}{c}\text { First cut-on } \\
\text { frequency }(\mathrm{Hz})\end{array}$ & $\begin{array}{c}\text { Mass per unit area } \\
\left(\mathrm{kg} / \mathrm{m}^{2}\right)\end{array}$ & $R_{w}(\mathrm{~dB})$ & $R_{\mathrm{A} 2}(\mathrm{~dB})$ \\
\hline $3-1$ & 0.71 & 3 & 96 & & 34.3 & 24.3 \\
\hline $3-2$ & 1.00 & 5 & 84 & 20.3 & 32.7 & 25.7 \\
\hline $3-3$ & 1.34 & 7 & 78 & & 32.4 & 25.4 \\
\hline
\end{tabular}

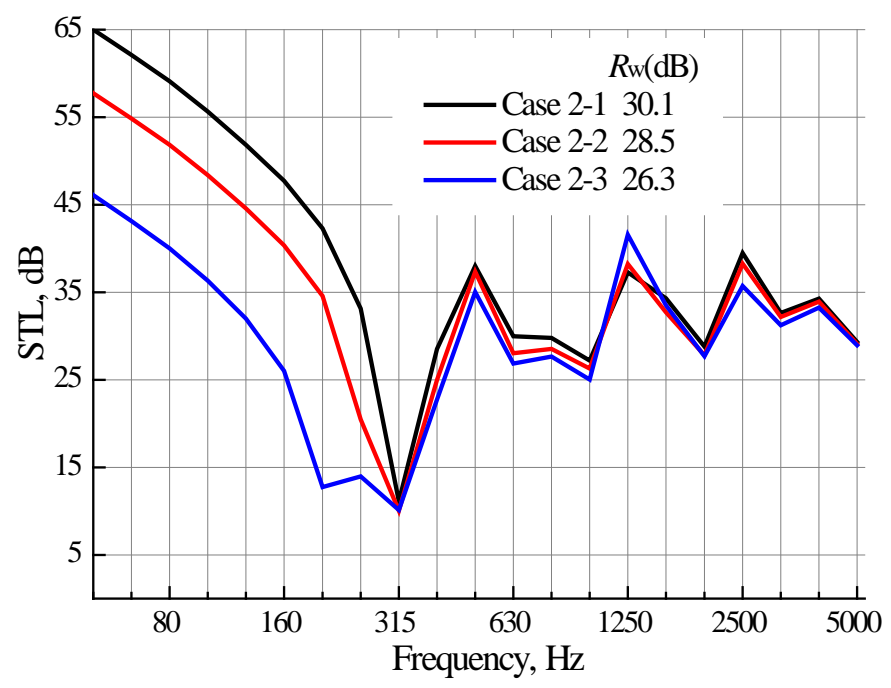

Figure B.6 Effect of width on diffuse field STL of cases 2-1 2-3 


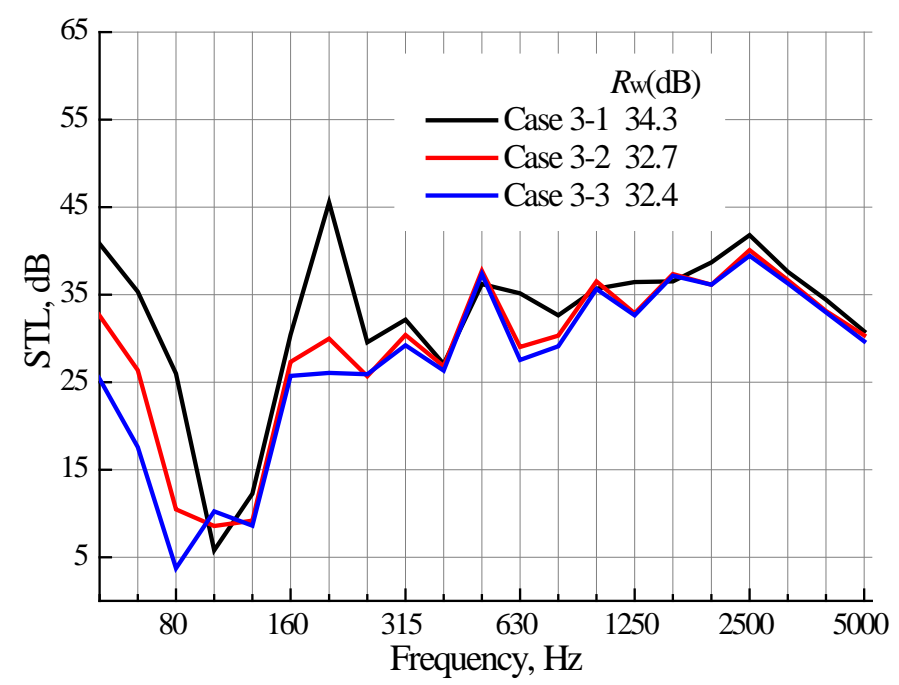

Figure B.7 Effect of width on diffuse field STL of cases 3-1 3-3

\section{B.3 Discussion}

In conclusion, both the boundary conditions and the width have an influence on the STL, mainly affecting the results near and below the first cut-on frequency. This can result in differences in the weighted STL, particularly if the stiffness-controlled region falls within the frequency bands 100 3150 Hz. 